NBSIR 86-3473

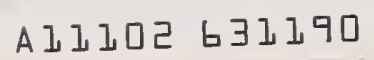

NATL INST OF STANDARDS \& TECH R.IC.

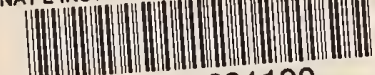

A11102631190

A11102631190 serv Domich, Paul D/The Internal Revenue Sers 1987 V19 C.1 NBS

\title{
The Internal Revenue Service Post-Of-Duty Location Modeling System - Programmer's Manual for Fortran Driver
}

Paul D. Domich, Richard H. F. Jackson, Marjorie A. McClain

\author{
U.S. DEPARTMENT OF COMMERCE \\ National Bureau of Standards \\ National Engineering Laboratory \\ Center for Applied Mathematics \\ Gaithersburg, MD 20899
}

July 1986

Issued February 1987

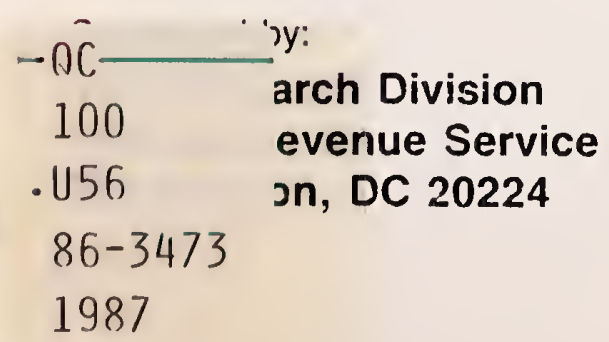



THE INTERNAL REVENUE SERVICE

POST-OF-DUTY LOCATION MODELING

SYSTEM - PROGRAMMER'S MANUAL FOR FORTRAN DRIVER

Paul D. Domich, Richard H. F. Jackson, Marjorie A. McClain

U.S. DEPARTMENT OF COMMERCE

National Bureau of Standards

National Engineering Laboratory

Center for Applied Mathematics

Gaithersburg, MD 20899

July 1986

Issued February 1987

Sponsored by:

The Research Division

Internal Revenue Service

Washington, DC 20224

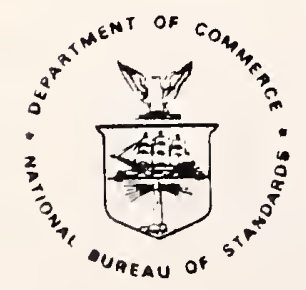

U.S. DEPARTMENT OF COMMERCE, Malcolm Baldrige, Secretary NATIONAL BUREAU OF STANDARDS, Ernest Ambler, Director 
1 


\section{$\underline{\text { ABSTRACT }}$}

This report is a programmer's manual for a microcomputer package which was designed by the National Bureau of Standards to assist the Internal Revenue Service in choosing locations for its posts-of-duty which will minimize costs to the IRS and to the taxpayer. The package was written in two sections of code, one in FORTRAN and the other in PASCAL. This manual describes the FORTRAN driver which handles graphics displays and controls input and output for the solution procedure.

Keywords: facility location, interactive graphics, personal computer, microcomputer, Graphical Kernel System (GKS) 


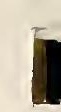

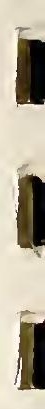

,

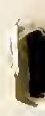

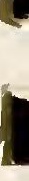




\title{
TABLE OF CONTENTS
}

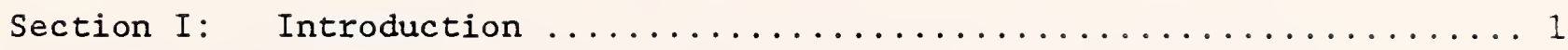

Section II: Software Requirements $\ldots \ldots \ldots \ldots \ldots \ldots \ldots \ldots \ldots \ldots \ldots \ldots$

Section III: Description of Data File Initialization Programs ........4

Section IV: Overview of System Programs $\ldots \ldots \ldots \ldots \ldots \ldots \ldots \ldots \ldots$

Section $V:$ Description of FORTRAN Routines $\ldots \ldots \ldots \ldots \ldots \ldots \ldots$
\end{abstract}




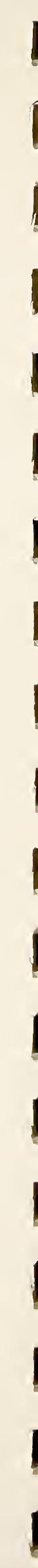


The Internal Revenue Service Post-of-Duty Location System is a microcomputer package designed to assist IRS district planners in choosing locations for posts-of-duty (POD's) which will minimize costs to the IRS and to the taxpayer. The package uses color graphics in performing tasks such as displaying maps of workload, setting user options to initialize location problems, and displaying solutions to location problems.

This manual is one of a series of reports documenting the POD location system. The reports in the series are as follows.

\section{1) The Internal Revenue Service Post-of-Duty Location Modeling System:} Final Report

This report describes the post-of-duty location problem and its mathematical model. It discusses the types of data which are considered in calculating costs, describes the methods used to solve the location problem, and gives a brief introduction to the computer implementation of the model. (NBS Contact: Richard H. F. Jackson)

2) The Internal Revenue Service Post-of-Duty Location Modeling System: User's Manual

This report is a user's guide for the post-of-duty location computer system. It gives hardware and software requirements, instructions for installing the system, descriptions of data files, and detailed instructions for operating the system. (NBS Contact: Marjorie A. McClain)

3) The Internal Revenue Service Post-of-Duty Location Modeling System: Programmer's Manual for FORTRAN Driver

The post-of-duty location program is written in two sections of code, one in FORTRAN and the other in PASCAL. This report describes the FORTRAN driver which handles graphics displays and controls input and output for the solution procedure. The report includes an alphabetical list of the FORTRAN routines, describing the purpose, the calling sequence and the variables of each routine. (NBS Contact: Marjorie A. McClain)

4) The Internal Revenue Service Post-of-Duty Location Modeling System: Programmer's Manual for PASCAL Solver

This report describes the second part of the post-of-duty location program, the PASCAL solver. It discusses the algorithms and data structures used to solve a location problem. (NBS Contact: Paul D. Domich) 
It is assumed that the reader of this programmer's manual is thoroughly familiar with IBM-PC DOS, with the FORTRAN language, and with the POD

location system User's Manual.

Note: Reference to a tradename or product in this report does not imply endorsement by the National Bureau of Standards. 


\section{Section II: Software Requirements}

The following software is required to be able to use and make changes to the POD location system programs.

1) IBM-PC DOS (Version 2.1 or later)

2) IBM Professional FORTRAN (Version 1.00)

3) Turbo PASCAL (Turbo-87 Version 3.0)

4) IBM Graphical Kernel System (Version 1.00)

(GKS includes the Virtual Device Interface and device drivers. See the User's Manual for information on how to set up the device drivers in the AUTOEXEC.BAT and CONFIG.SYS files.)

5) Source code for the POD location system, contained in the following files.

Data File Initialization Programs -TEMPZIP.BAS

UNFORM. FOR

SAVCEN.FOR

TEMPSTE.BAS

BINSTE . FOR

System Driver Programs ..

LOCATE. BAT

DRIVER.FOR

IRS . FOR

GKSUTIL.FOR

System Solver Programs -.

SOLVER. PAS

INIT . PAS

DSTRUCT. PAS

GREEDY.PAS

INTCHG. PAS

PODCLR. PAS

FIVCLR. PAS

6) Executable code for the POD location system, contained in the following files.

Data File Initialization Programs --

TEMPZIP.BAS

UNFORM. EXE

SAVCEN. EXE

TEMPSTE.BAS

BINSTE. EXE

System Driver Programs --

LOCATE. BAT

DRIVER. EXE

System Solver Program --

SOLVER.COM

Only a subset of this software is required for a user who just wants to run the system and not make any changes to it. See the User's Manual for user software requirements and also for general hardware requirements. 
The POD location system requires the use of zip code boundary coordinates obtained from a commercial vendor. This data must be processed when the system is first installed to convert it to a useable format. The following program files are used in the initialization process.

\section{1) TEMPZIP.BAS}

This BASIC program reads a zip code boundary file from floppy disks and writes it onto a fixed disk. In the process, labels are removed and endof-record marks are added to make the file readable by a FORTRAN program.

2) UNFORM. FOR

This FORTRAN program reads the file created by TEMPZIP.BAS and converts it to an unformatted direct access file. This is done to allow faster data accessing.

3) SAVCEN FOR

This FORTRAN program calculates the centroid of each zip code by taking a weighted average of its boundary points. The centroids are stored in an unformatted direct access file which also contains five-digit zip code names and pointers to each zip code in the boundary file.

4) TEMPSTE.BAS

This BASIC program reads a state boundary coordinate file from a floppy disk and writes it onto a fixed disk. End-of-record marks are added.

5) BINSTE, FOR

This FORTRAN program reads the file created by TEMPSTE.BAS and converts it to an unformatted direct access file. Also, the state boundary coordinates are transformed to be in the same units as the zip code boundary coordinates.

Note: These coordinate files will eventually be replaced by files from another vendor, so the initialization programs will be completely rewritten. 
Section IV: Overview of System Programs

The POD location system is written in two separate sections of code. One section is written in FORTRAN and contains the code for drawing maps and initializing location problems. It allows the user to display workload, set up a location problem, and display the solution. The second section is written in PASCAL and contains the code for solving a location problem. Data is passed between the two sections of code by the use of files.

A batch file called LOCATE.BAT controls the flow of execution between the two sections of code. LOCATE. BAT first checks to see if files called ERRORS.GKS and EXITFILE.BAT exist from a previous run. If so, it erases them. Then LOCATE.BAT enters a loop which passes control between the FORTRAN section (stored in DRIVER.EXE) and the PASCAL section (stored in SOLVER.COM). DRIVER is always entered first. Then, depending on actions taken by the user, either SOLVER is entered or an exit is taken from the loop. In the first case, after SOLVER has completed, control returns to DRIVER and the loop repeats. In the second case, a file called EXITFILE.BAT is created by DRIVER. It contains instructions for deleting work files created during the run. This new batch file is executed, and then LOCATE.BAT terminates.

The FORTRAN source code is contained in three files: DRIVER.FOR, IRS.FOR and GKSUTIL.FOR. DRIVER.FOR contains the main program DRIVER along with most of the high-level subroutines. IRS.FOR contains mostly intermediate-level subroutines for drawing menus and maps. GKSUTIL.FOR contains low-level subroutines for working with GKS. A complete description of each subroutine is given in Section $V$.

If a change is made in a subroutine, it must be recompiled by typing "PROFORT filename", where "filename" is the name of the source code file containing the subroutine. Then the program must be relinked by typing "LINK DRIVER IRS GKSUTIL \GKS \PFGKS, , \PROFORT \PROFORT \GKS\GKS \GKS \PFGKS /S:5000/X:350". (This assumes that DRIVER.OBJ, IRS.OBJ and GKSUTIL.OBJ are stored in the current directory, Professional FORTRAN files are in a directory called \PROFORT and GKS files are in a directory call \GKS. These path names may be changed.) The result is a new executable file called DRIVER. EXE.

The PASCAL solver routines are described in "The Internal Revenue Service Post-of-Duty Location Modeling System: Programmer's Manual for PASCAL Solver". 
Section V: Description of FORTRAN Routines

This section contains brief descriptions of each of the FORTRAN routines. Information is provided on the purpose of the routine, the name of the file containing its source code, names of input and output variables, and names of programs called by the routine and programs which call it. The routines are listed in alphabetical order.

\section{SUBROUTINE BEEP:}

This subroutine beeps the speaker.

Source Code Location --

GKSUTIL.FOR

Programs Called - -

None

Calling Programs --

STEMAP

ZIPMAP

\section{SUBROUTINE BORDER(XMIN, XMAX, YMTN, MMAX):}

This subroutine draws a border around the current screen window. The provided window limits are slightly reduced before the border is drawn; otherwise some sides of the border may not appear because of roundoff error in the conversion from world coordinates to screen coordinates. (See the GKS manual for definitions of graphics terms.)

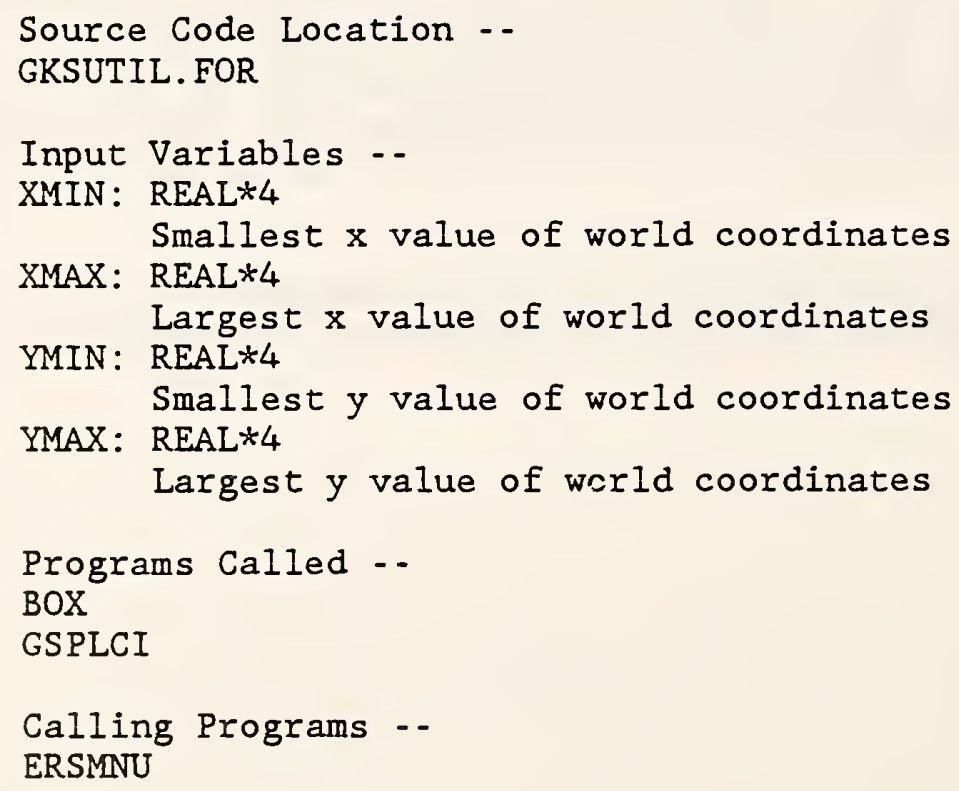


MAPKEY

MENU20

MENU21

MENU22

MENU23

SPLTWN

TOPMNU

ZIPMAP

\section{SUBROUTINE BOX(XMIN, XMAX, YMIN, MMAX):}

This subroutine draws a box. (See the GKS manual for definitions of graphics terms.)

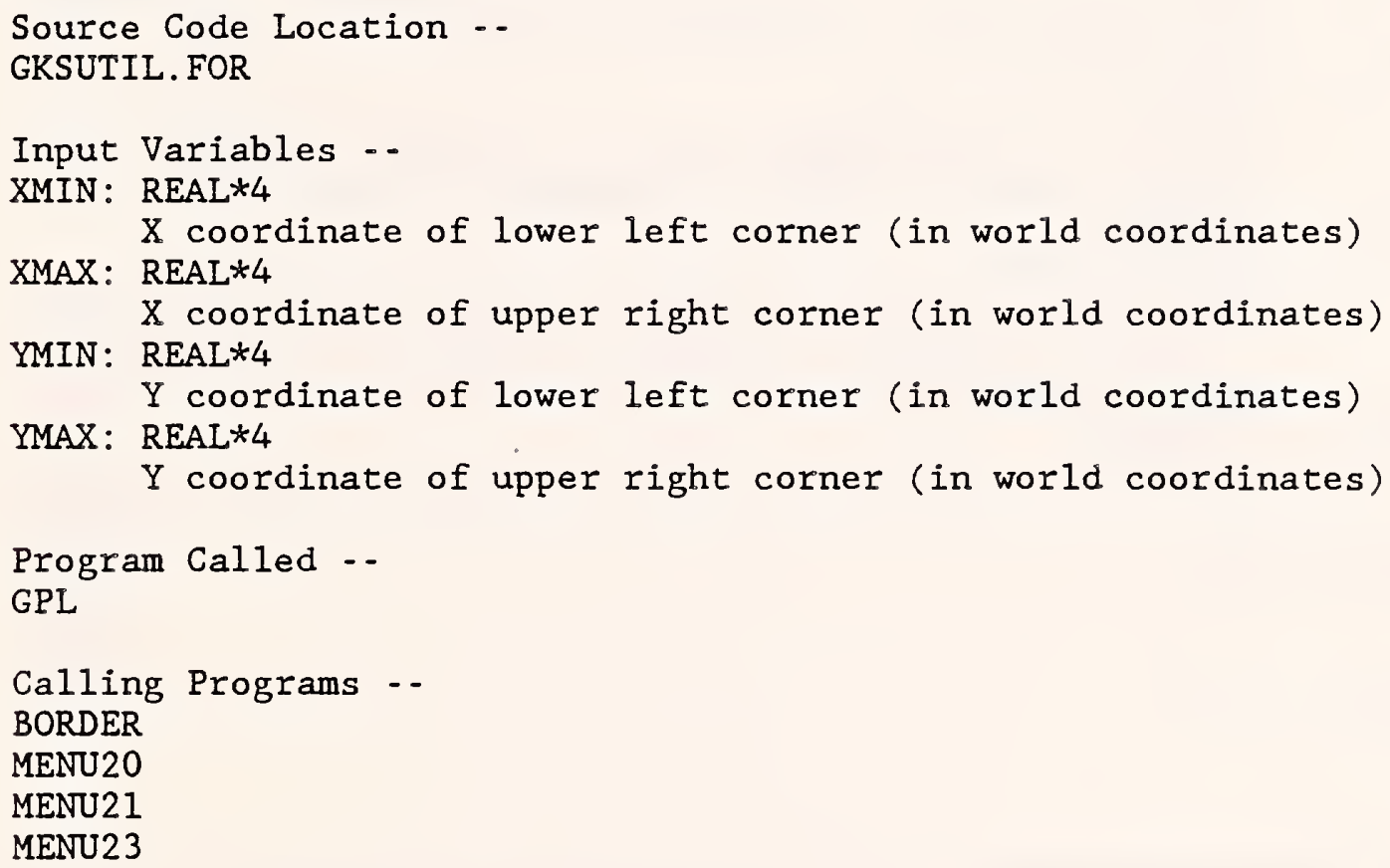

\section{SUBROUTINE CENSRT (IERR, STATE, MAXM, M, XCENT, YCENT, INDEX, PNT , ZIP5) :}

This subroutine reads the centroid file STATEXX.CEN and calls a heapsort program to sort the centroids according to increasing $\mathrm{x}$ and $\mathrm{y}$ coordinates. (This is done to speed up the process of searching for zip codes on a map. It also speeds up the drawing of maps.) Arrays are set up to store the following information from the file: centroids, pointers to the zip code boundary file, zip code index numbers, and five-digit zip code names. This subroutine is executed whenever the program DRIVER is entered.

Source Code Location --

IRS . FOR

Input Variables -. 


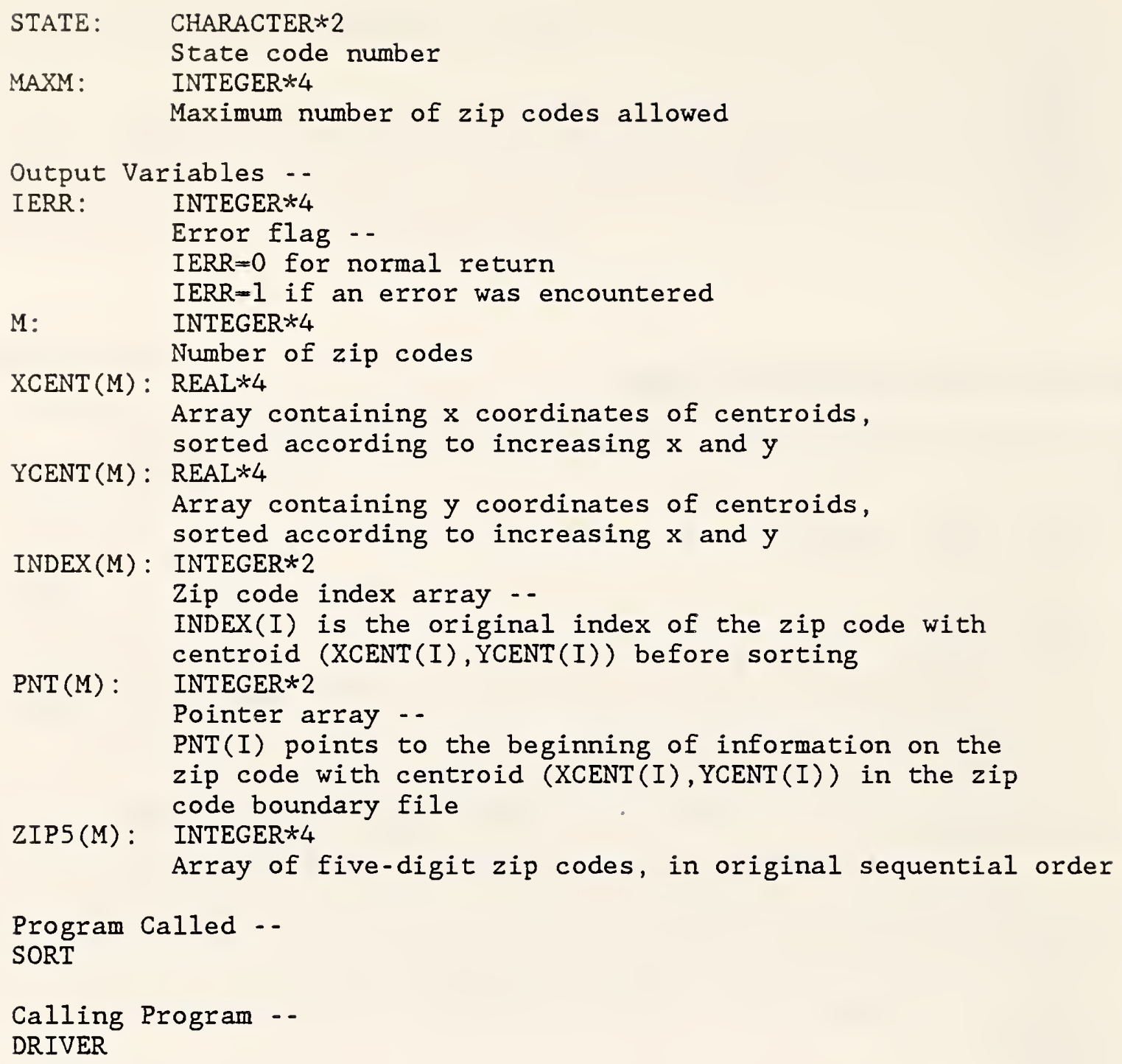

\section{SUBROUTINE CHOICE(WKID, CHDNR) :}

This subroutine initializes choice mode (function keys). To use the function keys, call GRQCH ("REQUEST CHOICE"). (See the GKS manual for definitions of graphics terms.)

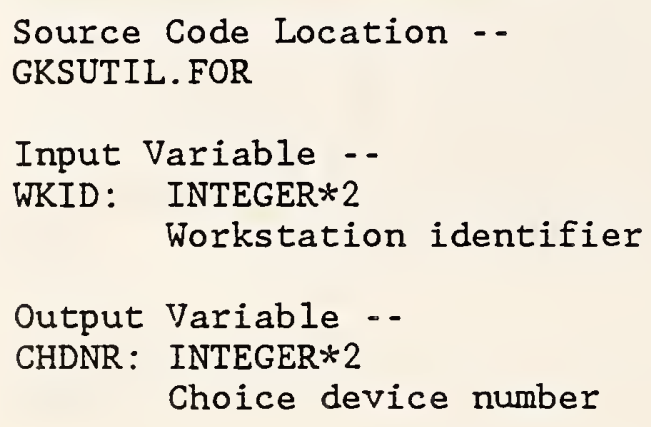


Program Called ..

GSCHM

Calling Programs ..

DISPLY

DRIVER

\section{SUBROUTINE CLSGKS(WKID):}

This subroutine closes GKS and resets the screen mode for text. (This requires the presence of ANSI.SYS in the CONFIG.SYS file. See the GKS manual for definitions of graphics terms.)

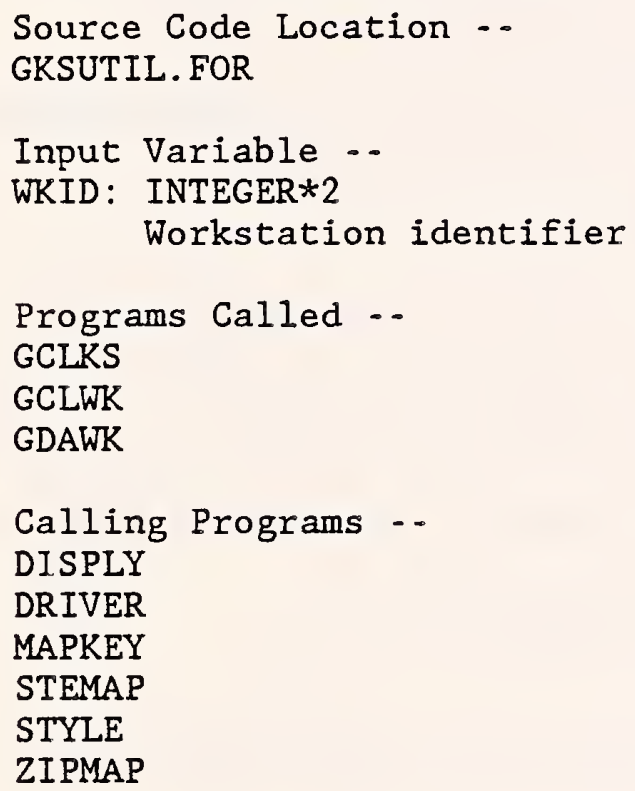

FUNCTION COSTFN (IMFFNC, WRK, IRSWT, IRSFCT, TXPWT, TXPFCT, MCLCST, TRVDIF, DIST, SQFCST, SQFT):

This function calculates the cost of assigning a zip code to a POD site. The cost is made up of travel costs and office space costs. Travel costs are based on the Individual Master File (IMF) workload generated by the zip code, its distance from the POD site, and the cost per mile. (Business Master File (BMF) data is not yet available.) However, the cost may be weighted by several user-supplied factors. Office space costs are based on the number of IMF returns generated by the zip code and the rental cost per square foot for office space at the POD site. (Warning: Office space costs are currently being computed incorrectly, since the required data is not yet available. The number of IMF returns examined is being used in place of the total number of IMF returns.) For further information on how costs are computed, see "The Internal Revenue Service Post-of-Duty Location Modeling System: Final Report". 


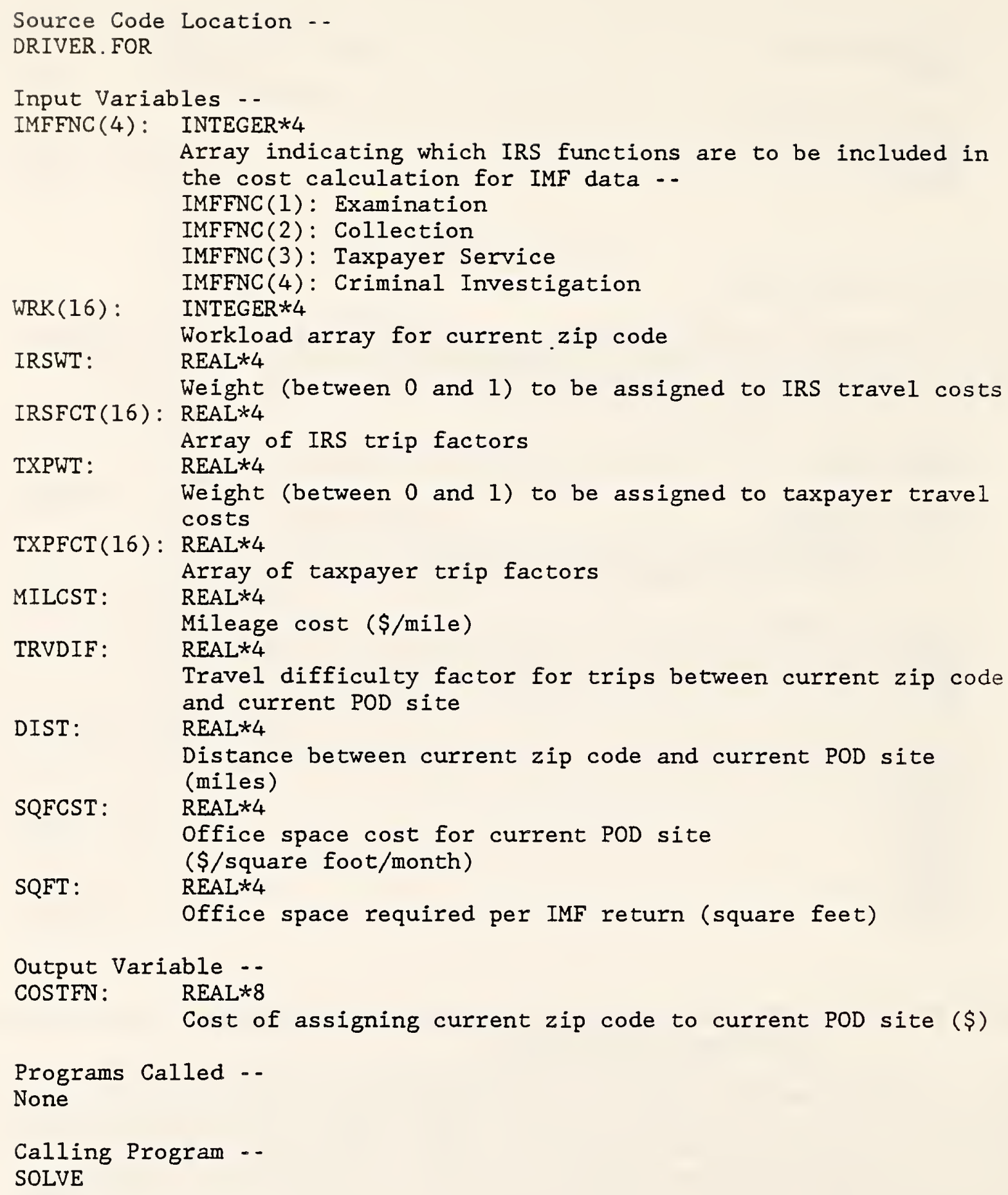


opposite corner of the box. (See the GKS manual for definitions of graphics terms.)

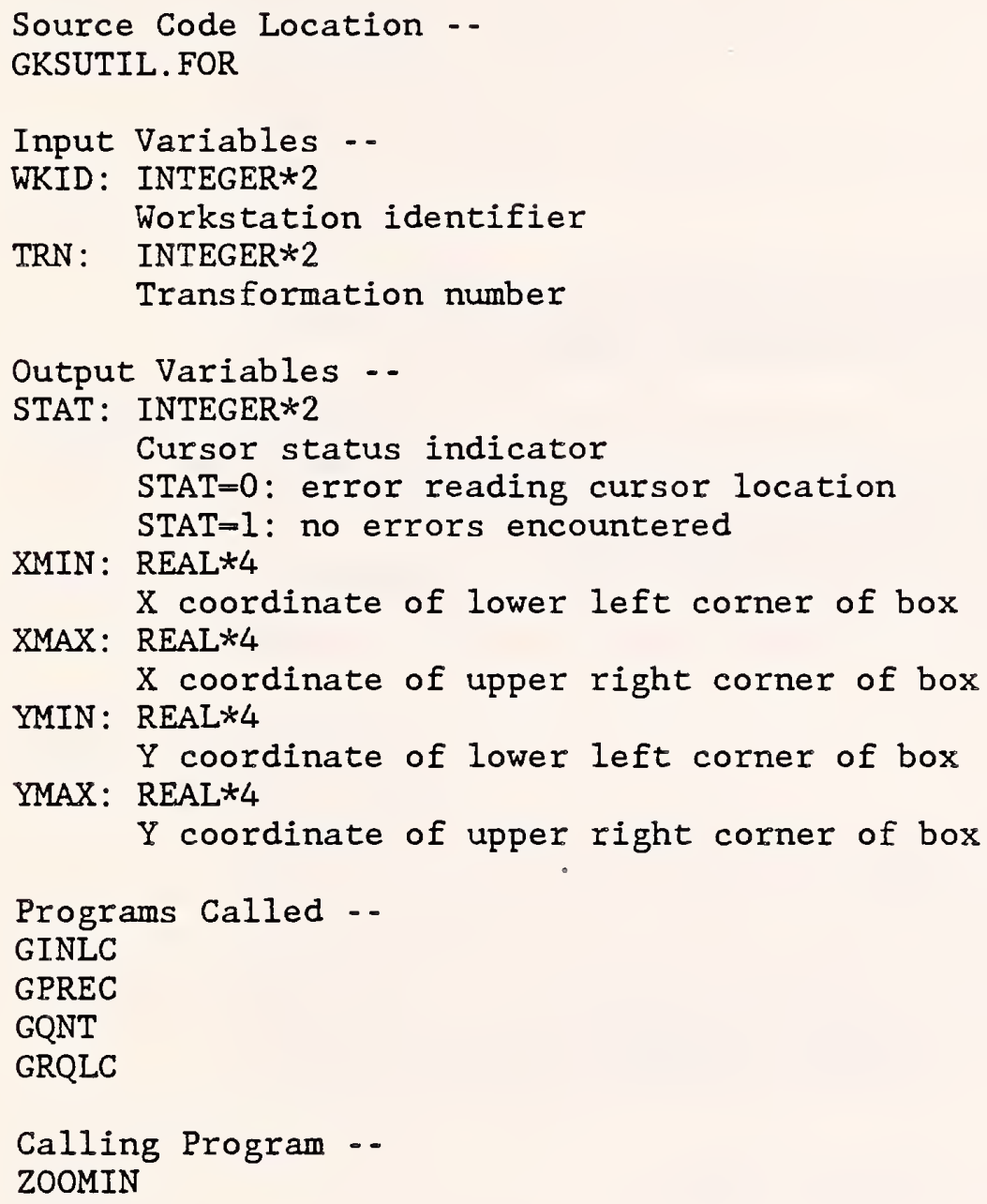

SUBROUTINE CURSOR (WKID, TRN, IPX, IPY):

This subroutine initializes a graphics cursor. To use the cursor, call GRQLC ("REQUEST LOCATOR"). (See the GKS manual for definitions of graphics terms.)

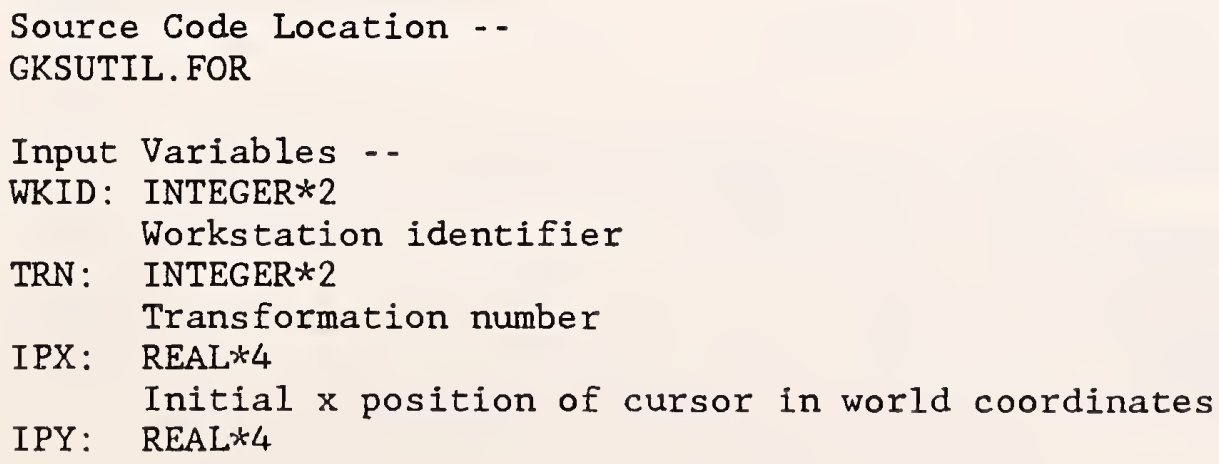


Initial y position of cursor in world coordinates

Programs Called - -

GINLC

GPREC

Calling Program - -

MAPKEY

SUBROUTINE DISPLY (IERR, STATE, PALETT, NCLRS, MENU, COLOR, MODIFY,

M, XCENT, YCENT, INDEX, PNT, ZIPCLR):

This subroutine is the driver for displaying maps. It uses GKS to draw a state map and then allows the user to zoom in or modify the colors on the map. The following common block is required by GKS: COMMON /GRACOM/SIZE, INTARY.

SIZE is an INTEGER*4 variable set equal to 2500 , and INTARY is an INTEGER*4 array of length 2500 .

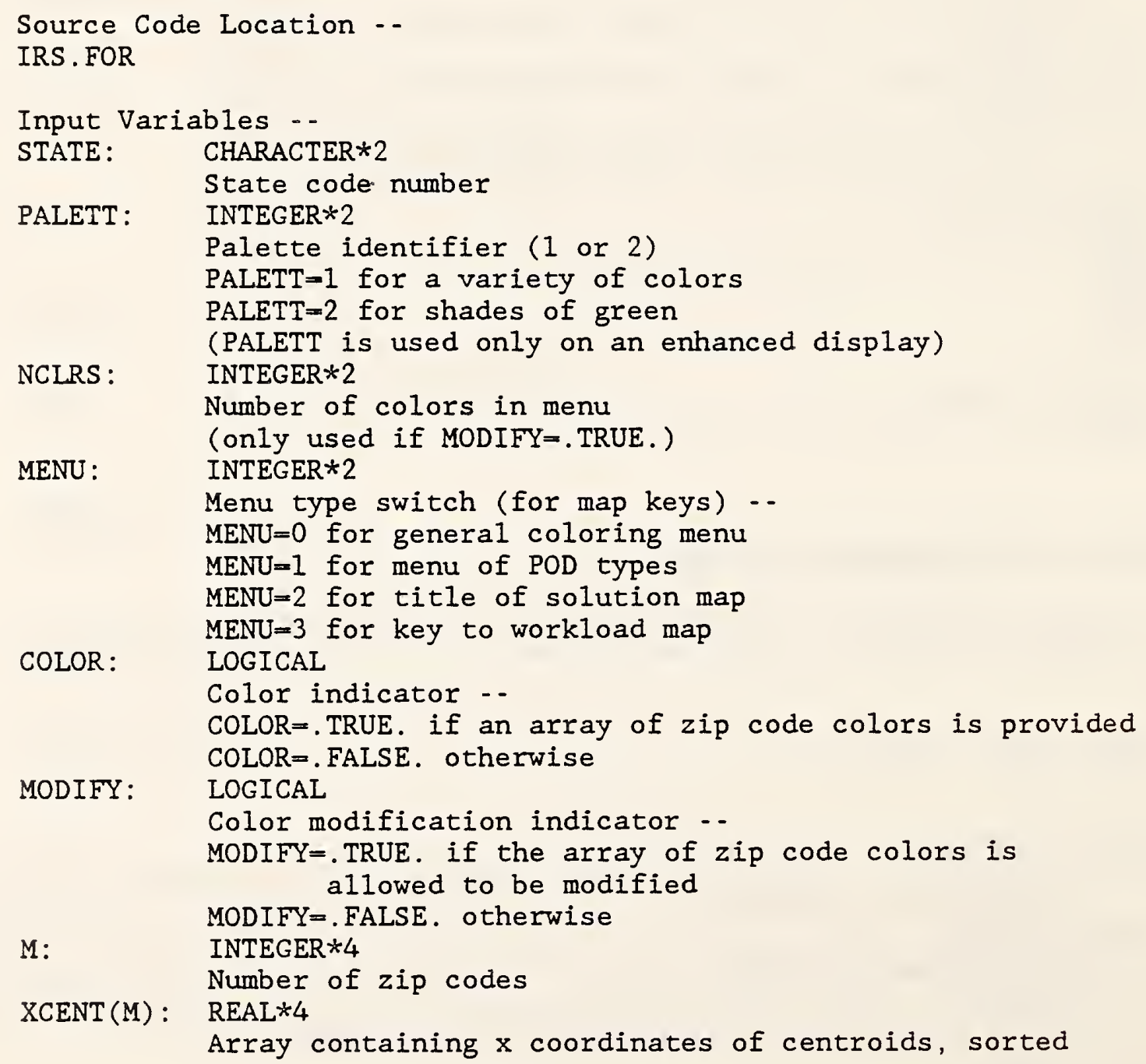




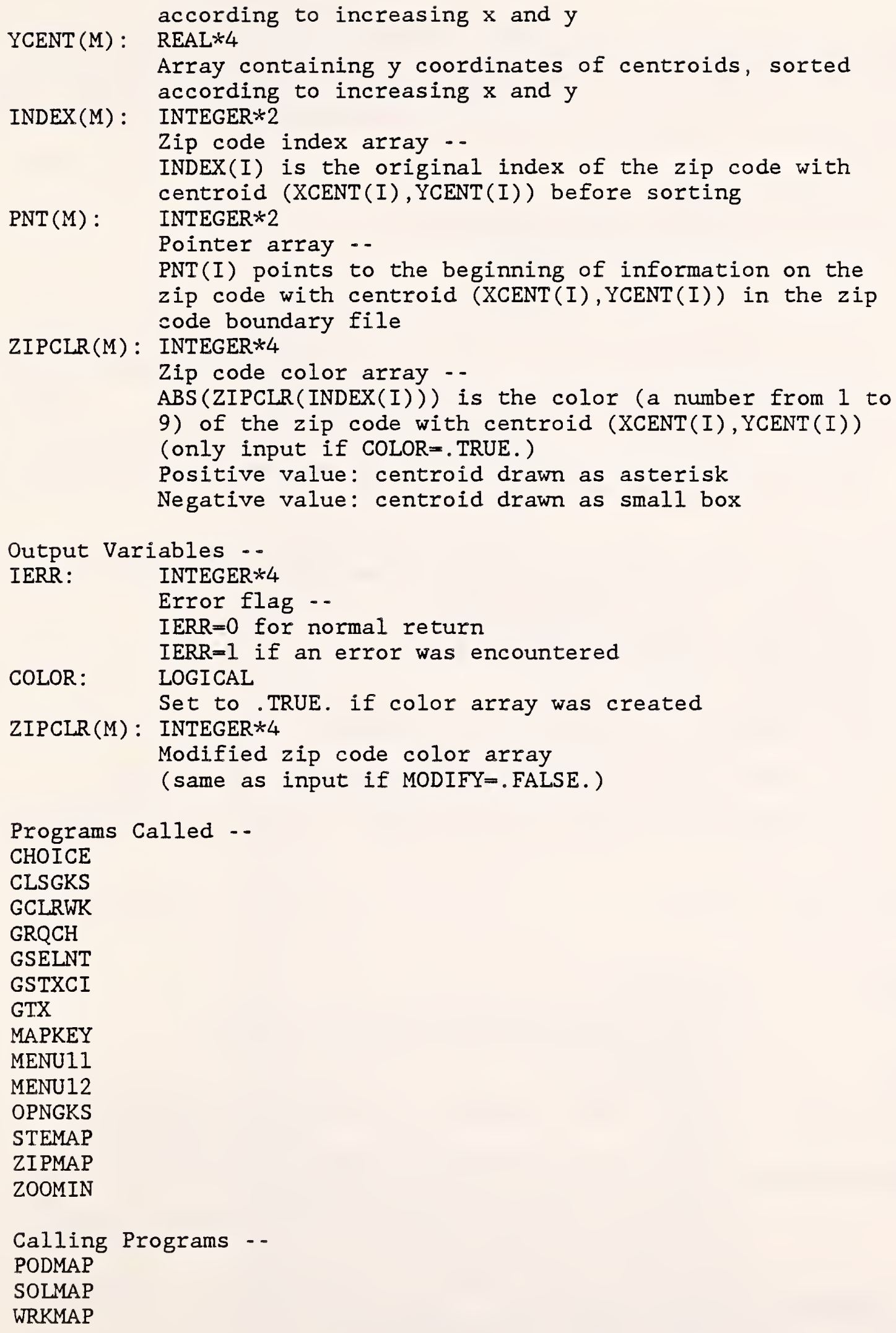


PROGRAM DRIVER:

This program is the driver for the POD location system. It first

initializes the report file STATEXX.REP and sets up data structures for

storing zip code information. Then it uses GKS to write the top-level menu

on the screen and allows the user to choose which phase of a problem to work

on. The possible choices are:

(1) Exit.

(2) Display workload.

(3) Display or modify initial POD sites.

(4) Solve for optimal POD locations.

(5) Display optimal POD locations.

The driver terminates in one of two possible ways:

(1) The user chooses "F1 - EXIT" from the top menu. In this case, a file called EXITFILE.BAT is created which signals the batch program LOCATE.BAT to leave the POD location system.

(2) The user chooses "F4 - SOLVE FOR OPTIMAL POD LOCATIONS" from the top menu. In this case, LOCATE. BAT passes control to the solution algorithm SOLVER.COM. When the solution procedure is finished, control returns to DRIVER. EXE.

The following files must exist to run the POD location system.

(In the following, "XX" should be replaced by the state code number.)

(1) STATEXX.STE: STATE BOUNDARY FILE

(2) STATEXX.ZIP: ZIP CODE BOUNDARY FILE

(3) STATEXX. CEN: ZIP CODE CENTROID FILE

(4) STATEXX.POD: POD SITE FILE

(5) STATEXX. WRK: WORKIOAD FILE

(See the User's Manual for information on the format of these files.)

The following common block is required by the graphics package GKS: COMMON /GRACOM/SIZE, INTARY.

SIZE is an INTEGER $* 4$ variable set equal to 2500 , and INTARY is an INTEGER $* 4$ array of length 2500 .

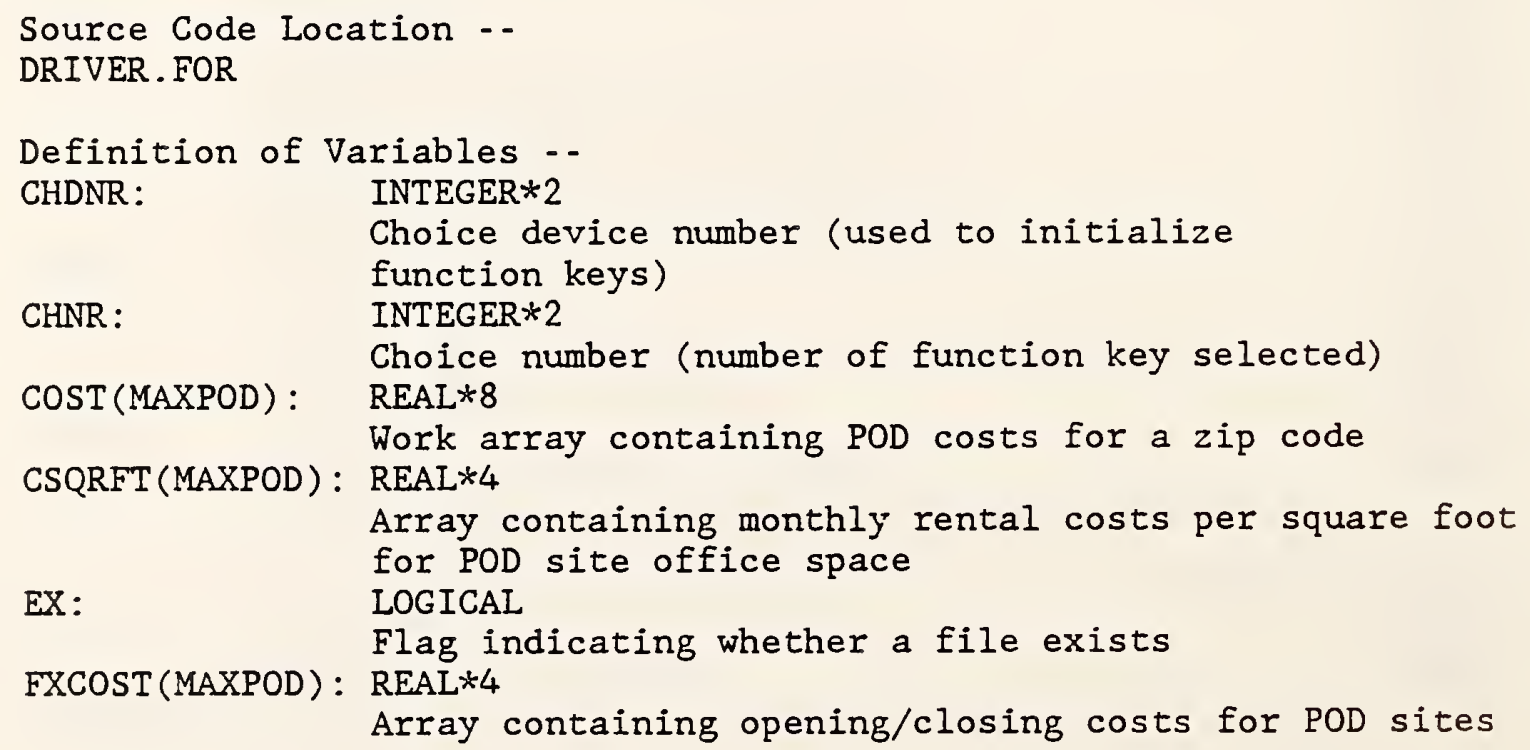




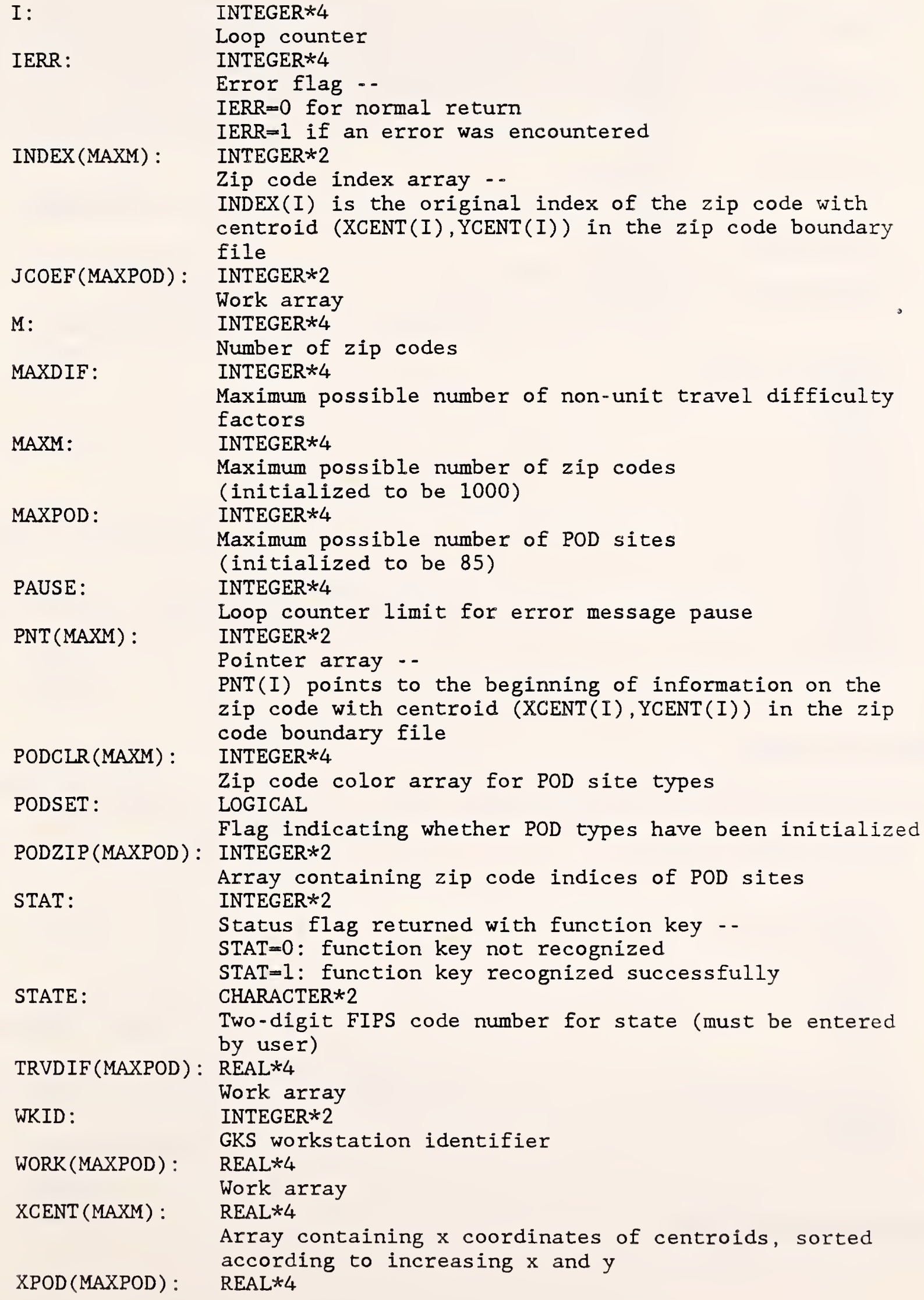




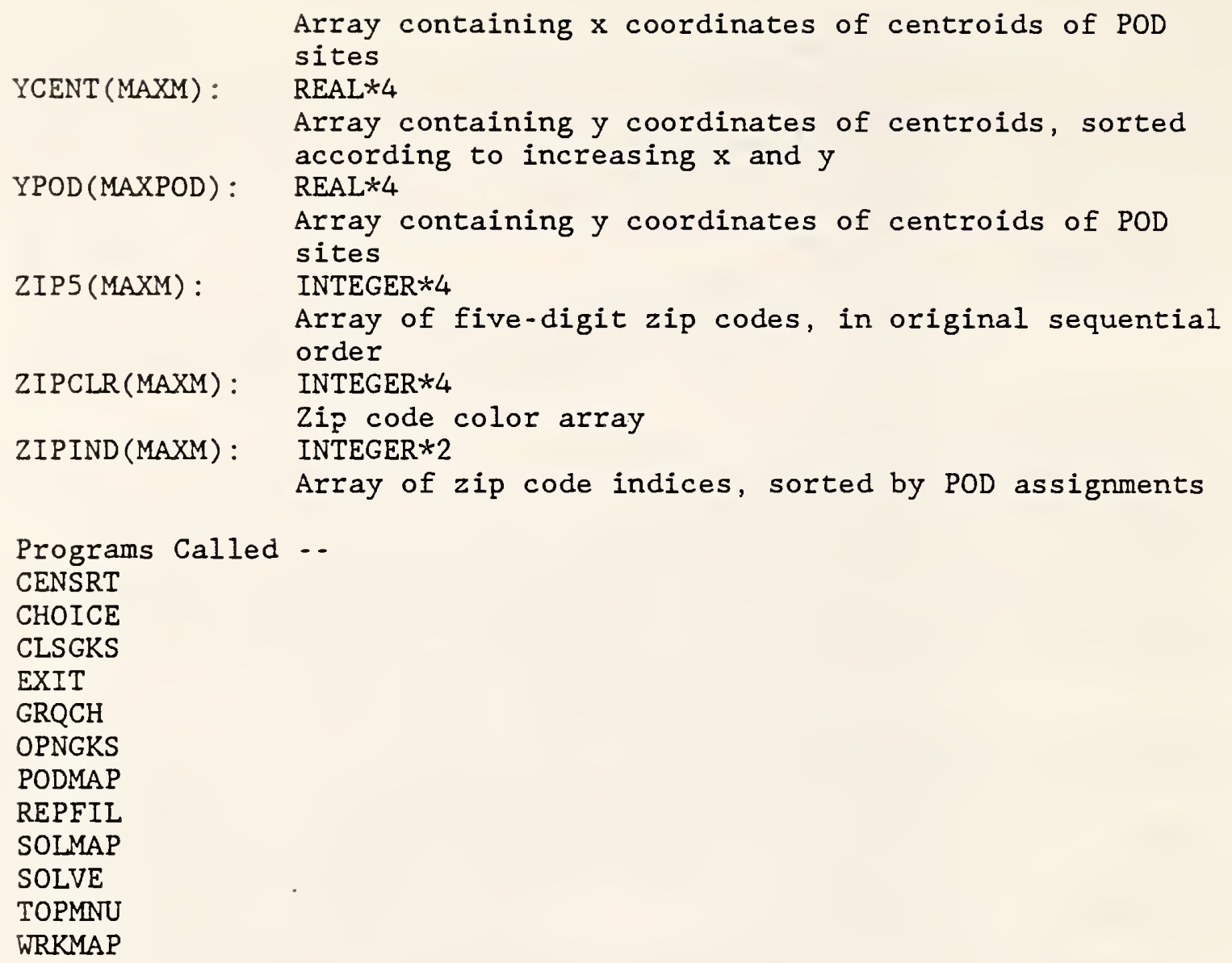

SUBROUTINE ERSMNU:

This subroutine erases the current menu from the left side of the screen.

Source Code Location --

IRS . FOR

Programs Called .-

BORDER

GFA

GQCNTN

GSELNT

STYLE

Calling Programs -. MAPKEY

ZOOMIN

SUBROUTINE EXIT(STATE): 
This subroutine is executed when the user chooses "F1 - EXIT" from the top menu. It creates a batch file called EXITFILE.BAT which contains instructions for deleting work files that were created during the run. After this subroutine has been completed, control returns to the batch file LOCATE.BAT, which checks to see if EXITFILE.BAT exists, executes it, and leaves the system.

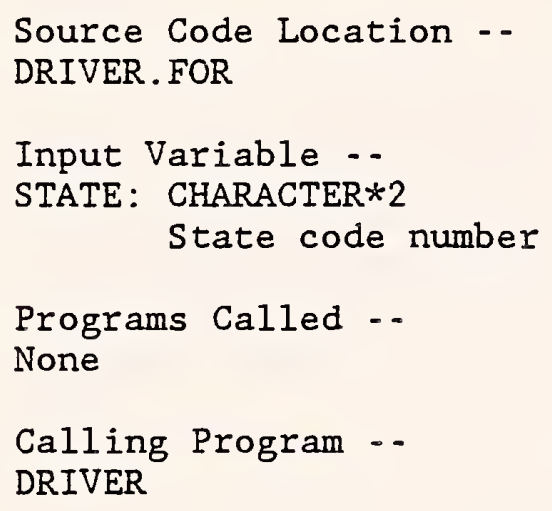

\section{SUBROUTINE GACWK(WKID):}

GKS routine -- "ACTIVATE WORKSTATION"

(See GKS manual for further information.)

Calling Program -.

OPNGKS

\section{SUBROUTINE GCLRS:}

GKS routine -. "CLOSE KERNEL SYSTEM"

(See GKS manual for further information.)

Calling Program -CLSGKS

\section{SUBROUTINE GCLRWK(WKID, COFL):}

GKS routine -- "CLEAR WORKSTATION"

(See GKS manual for further information.)

Calling Programs --

DISPLY

SPLTWN

ZOOMIN 
SUBROUTINE GCLWK(WKID):

GKS routine - - "CLOSE WORKSTATION"

(See GKS manual for further information.)

Calling Program ..

CLSGKS

SUBROUTINE GDAWK(WKID):

GKS routine -. "DEACTIVATE WORKSTATION"

(See GKS manual for further information.)

Calling Program --

CLSGKS

SUBROUTINE GEOFAC(DIFZIP, DIFPOD, DIFFAC, K1, NREC, STATE):

This subroutine allows the user to enter factors indicating the difficulty of travel between a $z i p$ code and a POD site. The values are stored in the file STATEXX.GDF.

Source Code Location --

DRIVER. FOR

Input Variables .-

KI:

INTEGER 44

Maximum number of non-unit travel difficulty factors

STATE:

CHARACTER $* 2$

State code number

Output Variables --

DIFZIP(NREC): INTEGER*4

Five-digit zip code array for use with travel difficulty factors

DIFPOD (NREC) : INTEGER 44

POD zip code array for use with travel difficulty factors

DIFFAC(NREC): REAL*4

Array of travel difficulty factors - -

DIFFAC(I) is the factor associated with $z$ ip code

$\operatorname{DIFZIP(I)}$ and POD site DIFPOD(I)

NREC: $\quad$ INTEGER $* 4$

Number of non-unit travel difficulty factors

Programs Called --

None

Calling Program --

SOLVE 
SUBROUTINE GETDAT (TYEAR, IMONTH, IDAY):

Professional FORTRAN routine -- "GET DATE"

(See Professional FORTRAN manual for further information.)

Calling Program --

REPFIL

SUBROUTINE GETTIM(IHOUR, IMIN, ISEC, IHUND) :

Professional FORTRAN routine -- "GET TIME"

(See Professional FORTRAN manual for further information.)

Calling Program --

REPFIL

SUBROUTINE GFA(N,PX,PY):

GKS routine -. "FILL AREA"

(See GKS manual for further information.)

Calling Programs --

ERSMNU

MAPKEY

MENU20

MENU21

MENU22

MENU23

ZIPMAP

SUBROUTINE GINRS (NTYPES, WNAMES, WTYPES, VERNUM) :

GKS routine -- "INITIALIZE GKS"

(See GKS manual for further information.)

Calling Program --

OPNGKS

SUBROUTINE CINLC(WKID , LCDNR, TNR, IPX, IPY , PET , XMIN , XMAX, YMIN , YMAX, LDR , DATREC) :

GKS routine - - "INITIALIZE LOCATOR"

(See GKS manual for further information.)

Calling Programs --

CRSBOX

CURSOR 
SUBROUTINE GOPKS (ERRFIL, SIZE) :

GKS routine - - "OPEN KERNEL SYSTEM"

(See GKS manual for further information.)

Calling Program -.

OPNGKS

SUBROUTINE GOPWK(WKID, CONID, WTYPE):

GKS routine -. "OPEN WORKSTATION"

(See GKS manual for further information.)

Calling Program ..

OPNGKS

SUBROUTINE GPL(N,PX, PY):

GKS routine -. "POLYLINE"

(See GKS manual for further information.)

Calling Programs -

BOX

MAPKEY

MENU11

MENU12

MENU20

MENU21

MENU22

MENU23

STEMAP

TOPMNU

ZIPMAP

SUBROUTINE GPM(N,PX, PY):

GKS routine - - "POLYMARKER"

(See GKS manual for further information.)

Calling Programs --

MAPKEY

STEMAP

ZIPMAP

SUBROUTINE GPREC (IL, IA , RL, RA, SL, MSTR, STR, MIDR, ERRIND , LDR, DATREC) : 
GKS routine -. "PACK DATA RECORD"

(See GKS manual for further information.)

Calling Programs --

CRSBOX

CURSOR

SUBROUTINE GQCF (WTYPE, ERRIND, NCOLI, COLA, NPCI):

GKS routine -- "INQUIRE COLOR FACILITIES"

(See GKS manual for further information.)

Calling Programs --

SETCOL

STEMAP

STYLE

TOPMNU

SUBROUTINE GQCNTN(ERRIND, CTNR):

GKS routine -- "INQUIRE CURRENT NORMALIZATION TRANSFORMATION NUMBER"

(See GKS manual for further information.)

Calling Programs --

ERSMNU

MENU11

MENU12

MENU20

MENU21

MENU22

MENU23

SUBROUTINE GQMDS (WTYPE, ERRIND, DCUNIT , RX, RY , LX, LY) :

GKS routine -. "INQUIRE MAXIMUM DISPLAY SURFACE SIZE"

(See GKS manual for further information.)

Calling Programs - -

SPLTWN

WINDOW

SUBROUTINE GQNT (TNR, ERRIND, WINDOW, VIEWPT) :

GKS routine -- "INQUIRE NORMALIZATION TRANSFORMATION"

(See GKS manual for further information.) 
Calling Programs --

CRSBOX

MAPKEY

SUBROUTINE GQTXX (WKID, PX, PY, STR, ERRIND, CPX, CPY, TXEXPX, TXEXPY) :

GKS routine - " "INQUIRE TEXT EXTENT"

(See GKS manual for further information.)

Calling Program --

SPLTWN

SUBROUTINE GRQCH (WKID, CHDNR, STAT, CHNR):

GKS routine -- "REQUEST CHOICE"

(See GKS manual for further information.)

Calling Programs -.

DISPLY

DRIVER

MAPKEY

SUBROUTINE GRQLC(WKID, LCDNR, STAT, TNR, PX, PY) :

GKS routine -- "REQUEST LOCATOR"

(See GKS manual for further information.)

Calling Programs --

CRSBOX

MAPKEY

SUBROUTINE GSCHM(WKID, CHDNR, MODE, ESW) :

GKS routine -- "SET CHOICE MODE"

(See GKS manual for further information.)

Calling Program --

CHOICE

SUBROUTINE GSCR(WRID, CI, CR, CG, CG):

GKS routine -- "SET COLOR REPRESENTATION"

(See GKS manual for further information.) 


\section{Calling Program .. \\ SETCOL}

\section{SUBROUTINE GSELNT(TNR):}

GKS routine -- "SELECT NORMALIZATION TRANSFORMATION"

(See GKS manual for further information.)

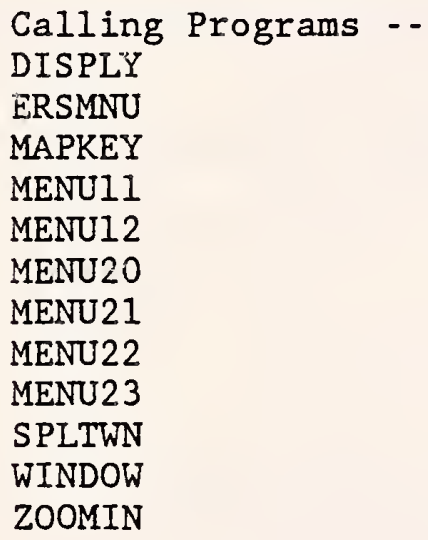

\section{SUBROUTINE GSFACI(COLI):}

GKS routine -- "SET FILL AREA COLOR INDEX"

(See GKS manual for further information.)

Calling Program -.

STYLE

SUBROUTINE GSFAIS(INTS):

GKS routine -- "SET FILL AREA INTERIOR STYLE"

(See GKS manual for further information.)

Calling Program --

STYLE

SUBROUTINE GSFASI(STYLI) :

GKS routine -- "SET FILL AREA STYLE INDEX"

(See GKS manual for further information.)

Calling Program --

STYLE 
SUBROUTINE GSMK(MTYPE):

GKS routine -- "SET POLYMARKER TYPE"

(See GKS manual for further information.)

Calling Programs -.

MAPKEY

STEMAP

ZIPMAP

SUBROUTINE GSPLCI(COLI):

GKS routine -- "SET POLYLINE COLOR INDEX"

(See GKS manual for further information.)

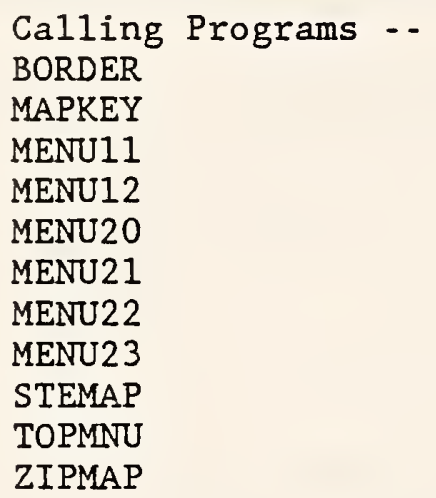

SUBROUTINE GSPMCI(COLI):

GKS routine -- "SET POLYMARKER COLOR INDEX" (See GKS manual for further information.)

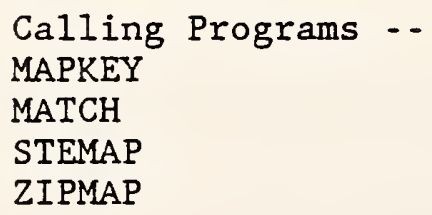

SUBROUTINE GSTXCI(COLI):

GKS routine -- "SET TEXT COLOR INDEX"

(See GKS manual for further information.)

Calling Programs - -

DISPLY

MAPKEY

MENU11 
MENU12

MENU20

MENU21

MENU22

MENU23

TOPMNU

ZOOMIN

SUBROUTINE GSVP (TNR, XMIN, XMAX, YMIN, YMAX):

GKS routine -. "SET VIEWPORT"

(See GKS manual for further information.)

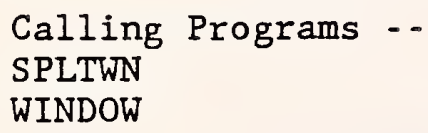

SUBROUTINE GSWKVP (WKID, XMIN, XMAX, YMIN, MMAX):

GKS routine -. "SET WORKSTATION VIEWPORT"

(See GKS manual for further information.)

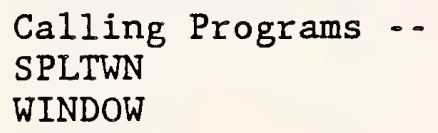

SUBROUTINE GSWKWN (WKID, XMIN, XMAX, YMIN, YMAX) :

GKS routine -- "SET WORKSTATION WINDOW"

(See GKS manual for further information.)

Calling Programs ..

SPLTWN

WINDOW

\section{SUBROUTINE GSWN(TNR, XMIN, XMAX, YMIN, YMAX) :}

GKS routine -- "SET WINDOW"

(See GKS manual for further information.)

Calling Programs -.

SPLTWN

WINDOW 
SUBROUTINE GTX (PX, PY, CHARS):

GKS routine -- "TEXT"

(See GKS manual for further information.)

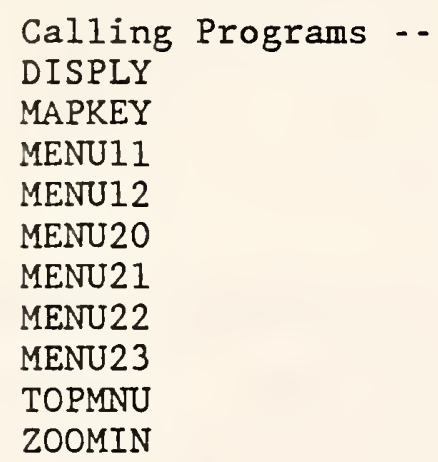

SUBROUTINE MAPKEY (IERR, MODIFY, TRN, PALETT , NCLRS , STATE , MENU, M, XCENT , YCENT, INDEX, PNT, ZIPCLR):

This subroutine displays a color key for the current zip code map. It allows the user to locate a zip code on the map with the cursor and have its five-digit name printed on the screen. (To do this, a search of the centroid array is done to find the closest centroid to the cursor position.) It may also allow the color of a zip code to be changed.

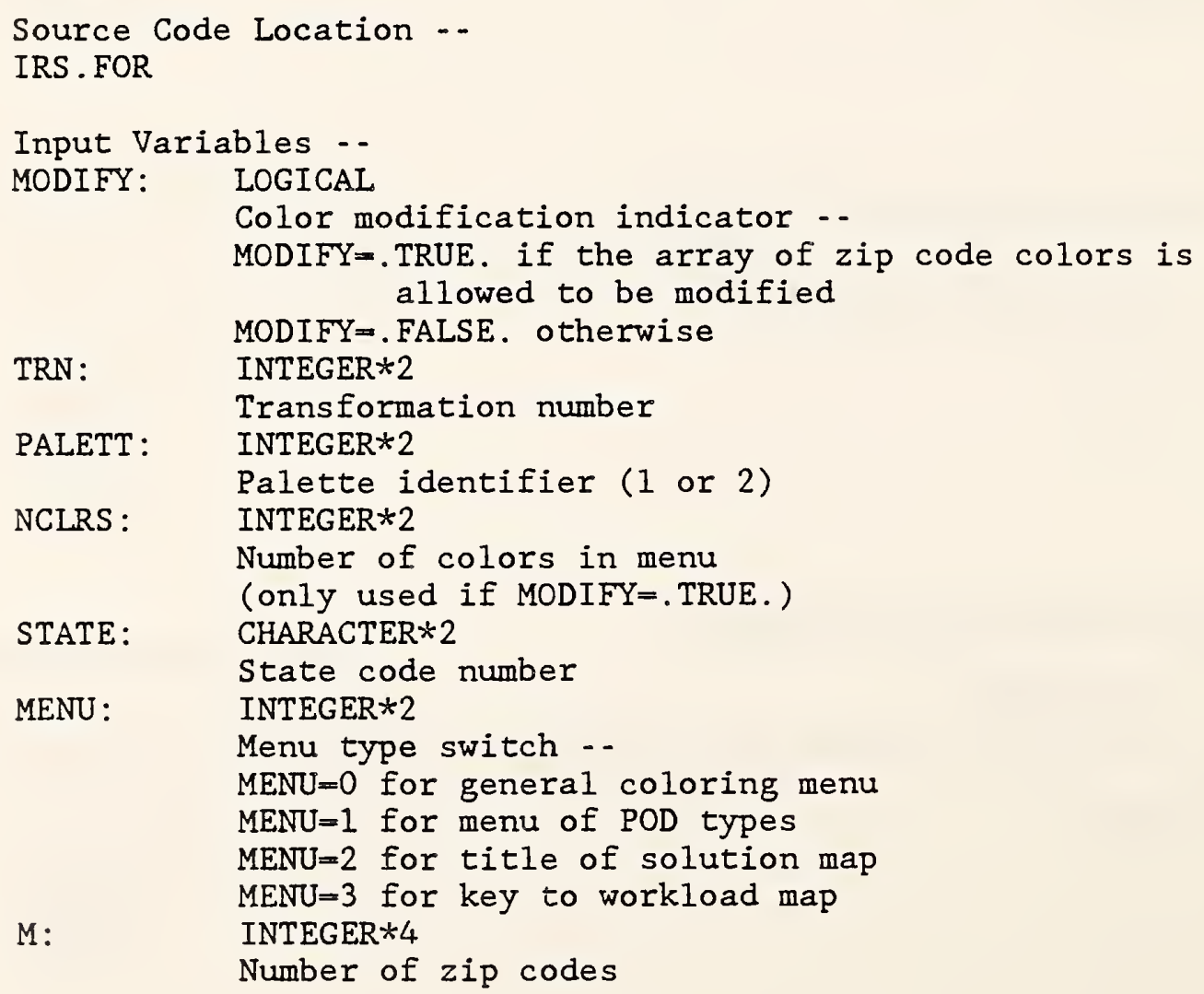




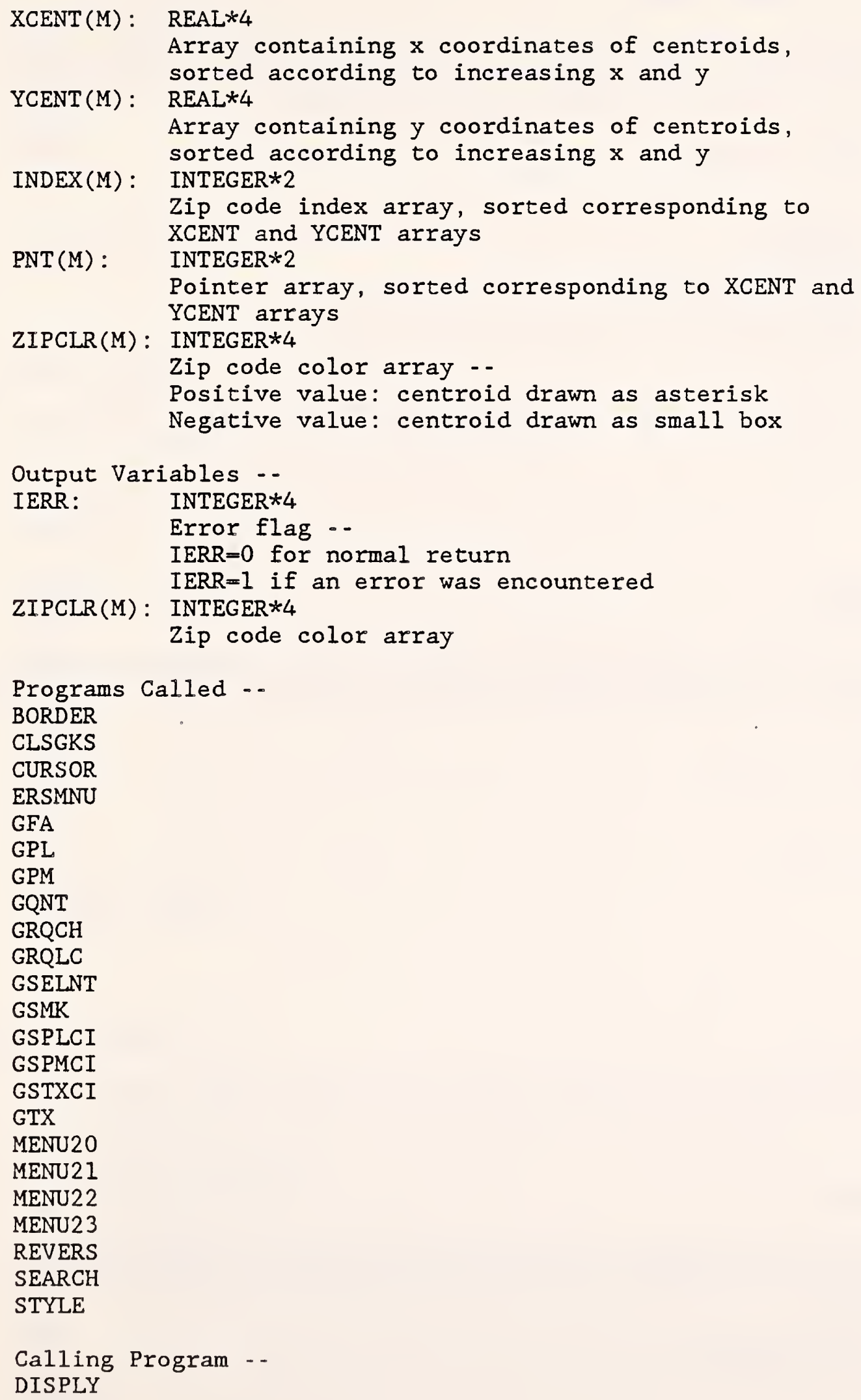


SUBROUTINE MATCH(PALETT, INDEX):

This subroutine sets a polymarker color index which will match the corresponding fill area color index (for an enhanced graphics display only). (See the GKS manual for definitions of graphics terms.)

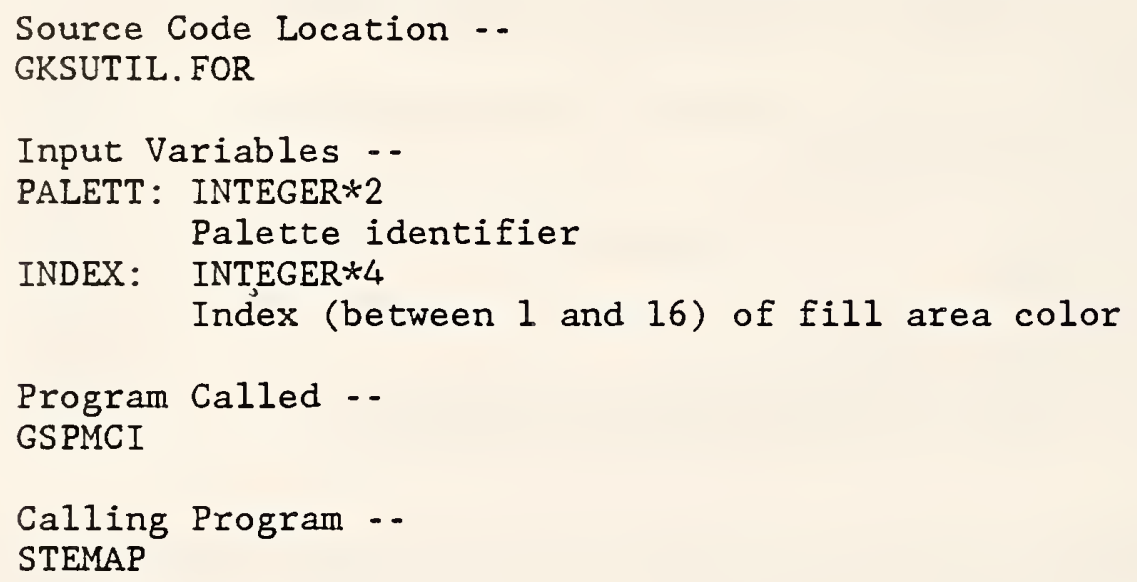

\section{SUBROUTINE MENU11:}

This subroutine writes a menu of display options on the left side of the screen. It lists the meaning of the function keys after a state border map has been drawn.

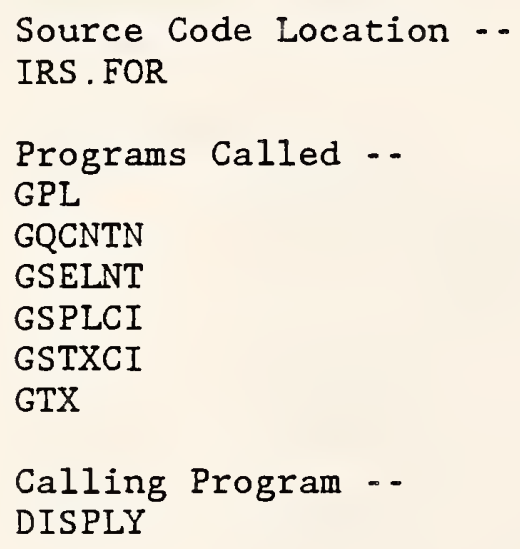

\section{SUBROUTINE MENU12:}

This subroutine writes a menu of display options on the left side of the screen. It lists the meaning of the function keys after a state zip code map has been drawn.

Source Code Location -IRS . FOR 


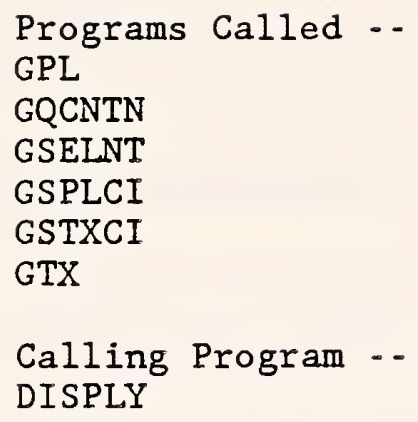

\section{SUBROUTINE MENU20:}

This subroutine writes a color key on the left side of the screen. It lists the colors associated with the function keys.

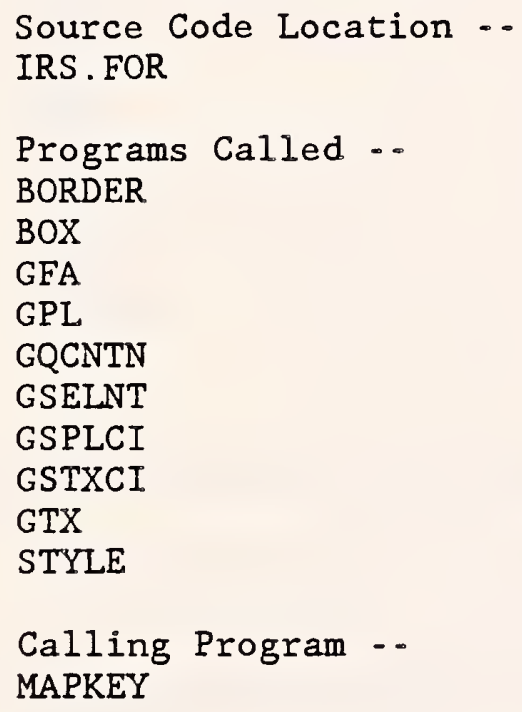

\section{SUBROUTINE MENU21:}

This subroutine writes a color key on the left side of the screen. It lists the colors and function keys associated with different types of POD sites.

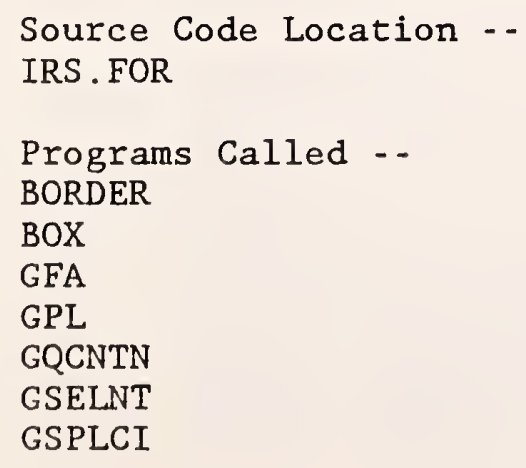


GSTXCI

GTX

STYLE

Calling Program - -

MAPKEY

\section{SUBROUTINE MENU22:}

This subroutine writes a key for the solution map on the left side of the screen.

Source Code Location -.

IRS . FOR

Programs Called -.

BORDER

GFA

GPL

GQCNTN

GSELNT

GSPLCI

GSTXCI

GTX

STYLE

Calling Program -.

MAPKEY

\section{SUBROUTINE MENU23:}

This subroutine writes a color key on the left side of the screen. It lists the colors and function keys used for displaying workload.

\section{Source Code Location -.}

IRS . FOR

Programs Called --

BORDER

BOX

GFA

GPL

GQCNTN

GSELNT

GSPLCI

GSTXCI

GTX

STYLE

Calling Program -. 


\section{MAPKEY}

\section{SUBROUTINE OPNGKS (WKID) :}

This subroutine opens GKS with one workstation of type "DISPLAY". Error messages will be written to a file called ERRORS.GKS. (See the GKS manual for definitions of graphics terms.)

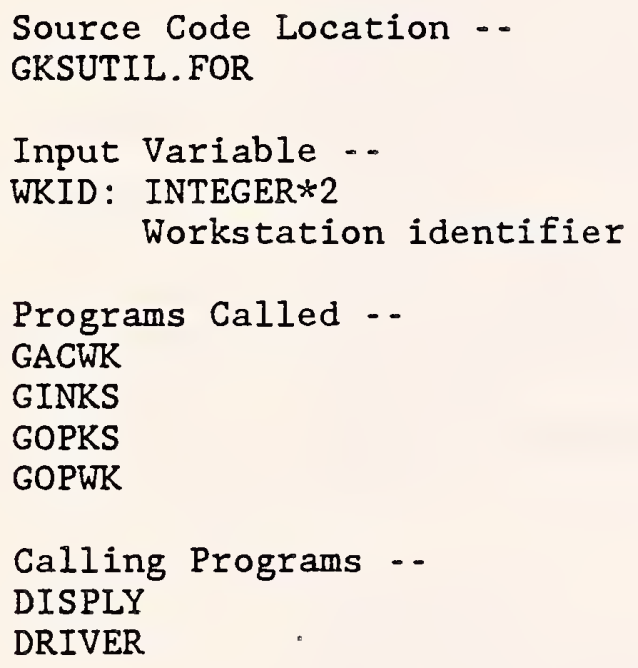

\section{SUBROUTINE OPTION(IO, DSTLIM, TXPWGT, IRSWGT, IMF, BMF) :}

This subroutine displays the default options for the cost calculation and allows the user to make changes.

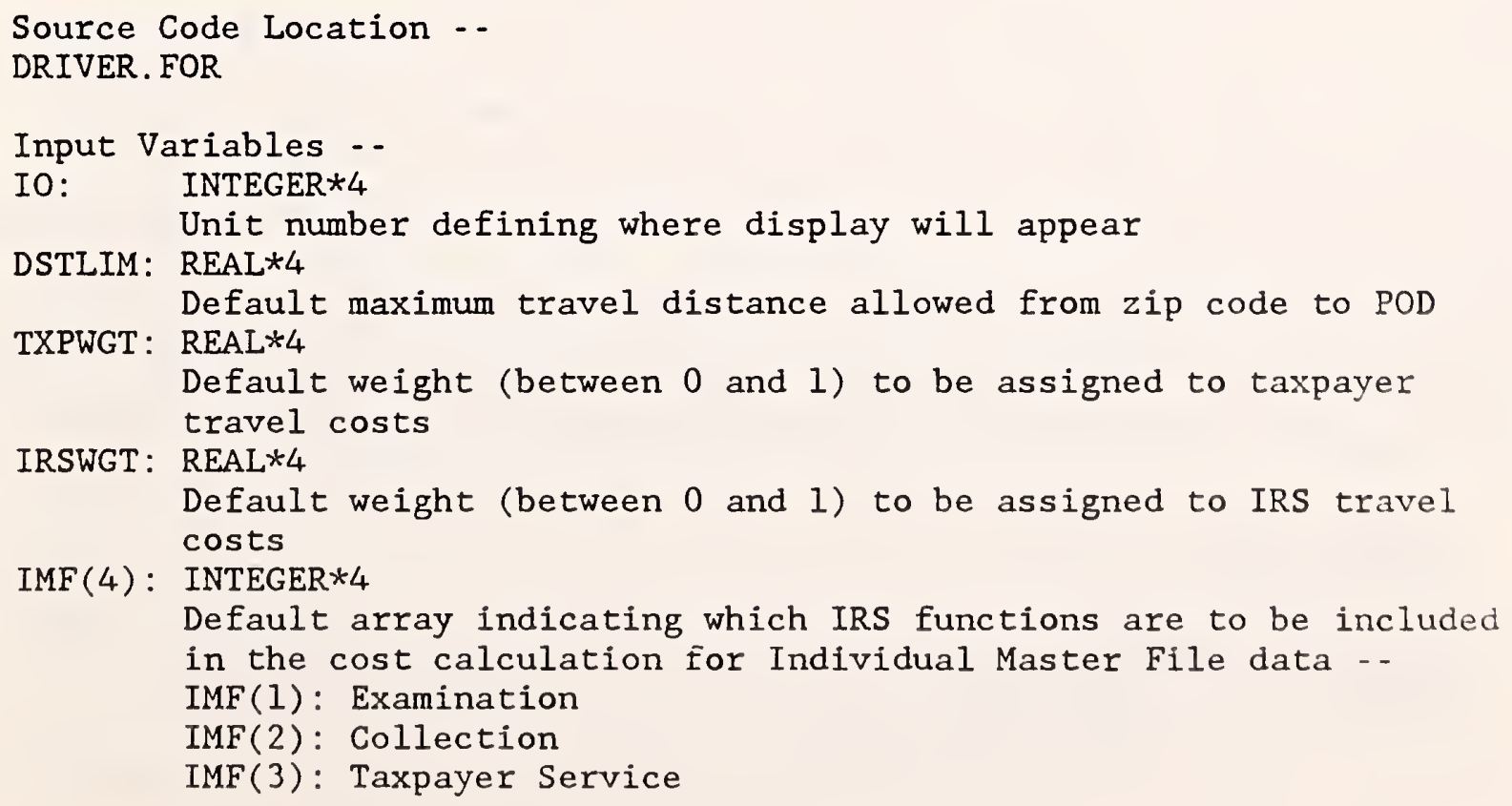




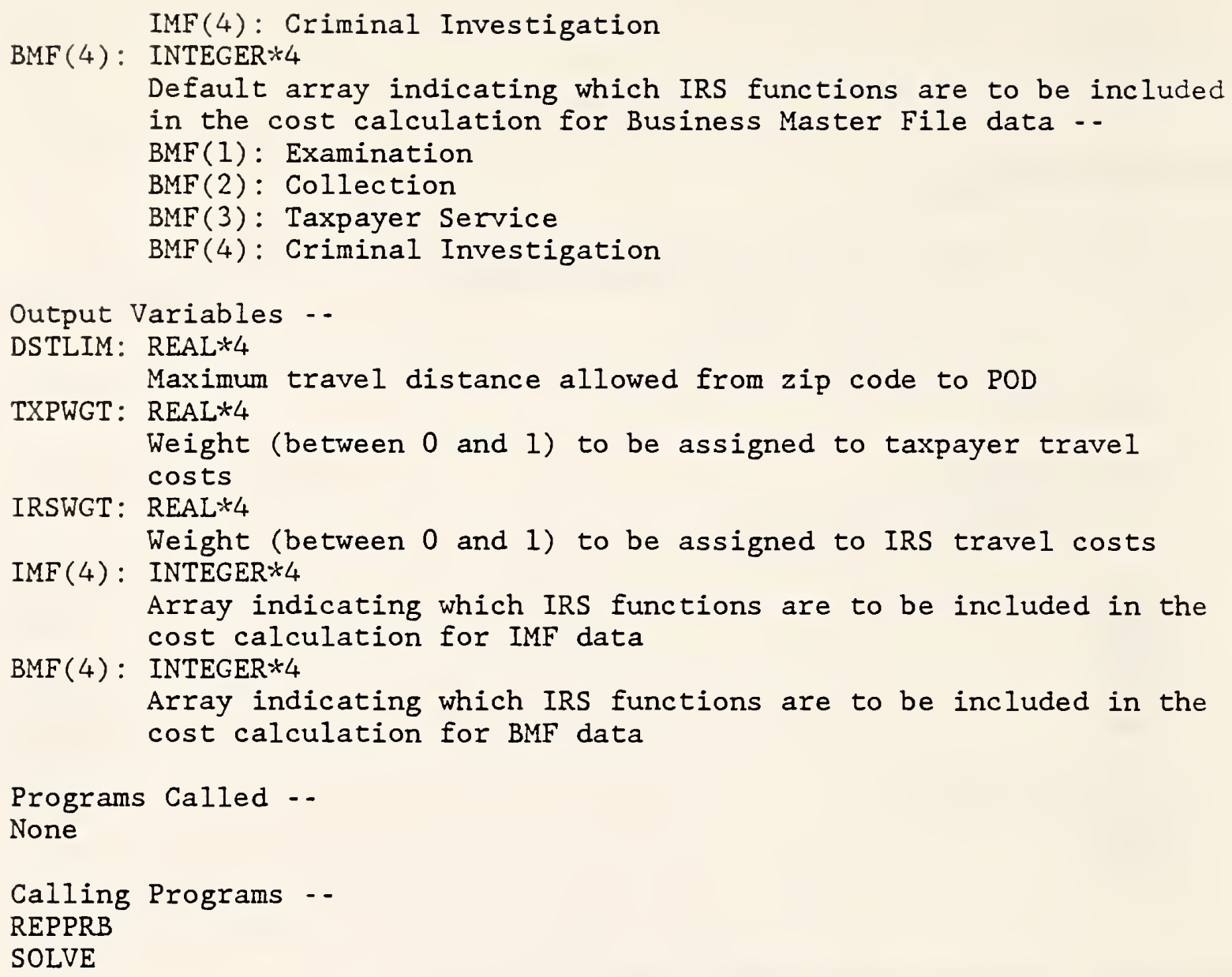

SUBROUTINE PODMAP (IERR, STATE, PAUSE, M, XCENT, YCENT, INDEX, PNT, ZIP5, ZIPCLR) :

This subroutine initializes the display of a map of current and potential POD sites. It is executed when the user chooses "F3 - DISPLAY OR MODIFY INITIAL POD SITES" from the top menu. First it reads the file STATEXX.POD to find which zip codes are allowed to be POD sites and which zip codes currently are POD sites. Color \#1 (background) is assigned to zip codes which cannot be POD sites, color \#2 is assigned to potential POD sites, and color \#3 is assigned to current POD sites. (Note: A negative color number indicates that the centroid will be drawn as a small box; otherwise the centroid is an asterisk.) Then these colors are passed in an array to the subroutine DISPLY, which draws the map and lets the user change the colors. The new colors are returned in the original array. Color \#4 in the new array indicates a zip code which the user has made a fixed POD site.

Source Code Location - -

DRIVER . FOR

Input Variables --

STATE: $\quad$ CHARACTER $* 2$

State code number 


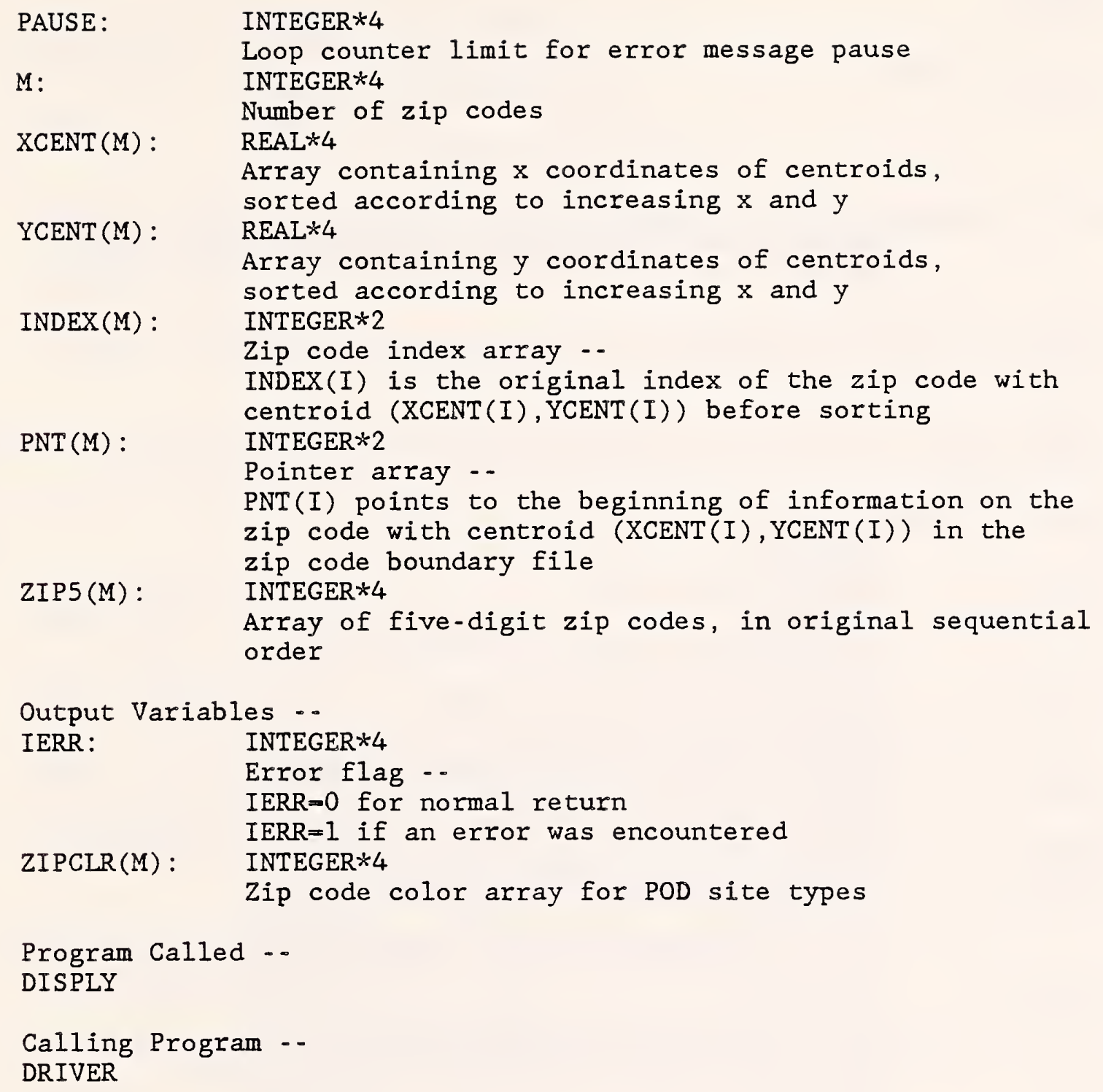

\section{SUBROUTINE REPFIL(STATE):}

This subroutine initializes the report file. Either a new report file is created or information is appended to an existing report file. A report header is written giving the date and time. The report file is assigned to unit 12 , which remains open after returning from the subroutine.

Source Code Location - -

DRIVER. FOR

Input Variable - -

STATE: CHARACTER $* 2$

State code number

Programs called -- 
GETDAT

GETTIM

Calling Program --

DRIVER

SUBROUTINE REPPRB (M, ZIPCLR, ZIP5, DSTLIM, IRSWT, TXPWT, IMFFNC, BMFFNC, NREC, DIFZIP , DIFPOD , DIFFAC , FXCOST , CSQRFT, SQFT, MILCST , IRSFCT, TXPFCT):

This subroutine writes information on the problem initialization into the report file.

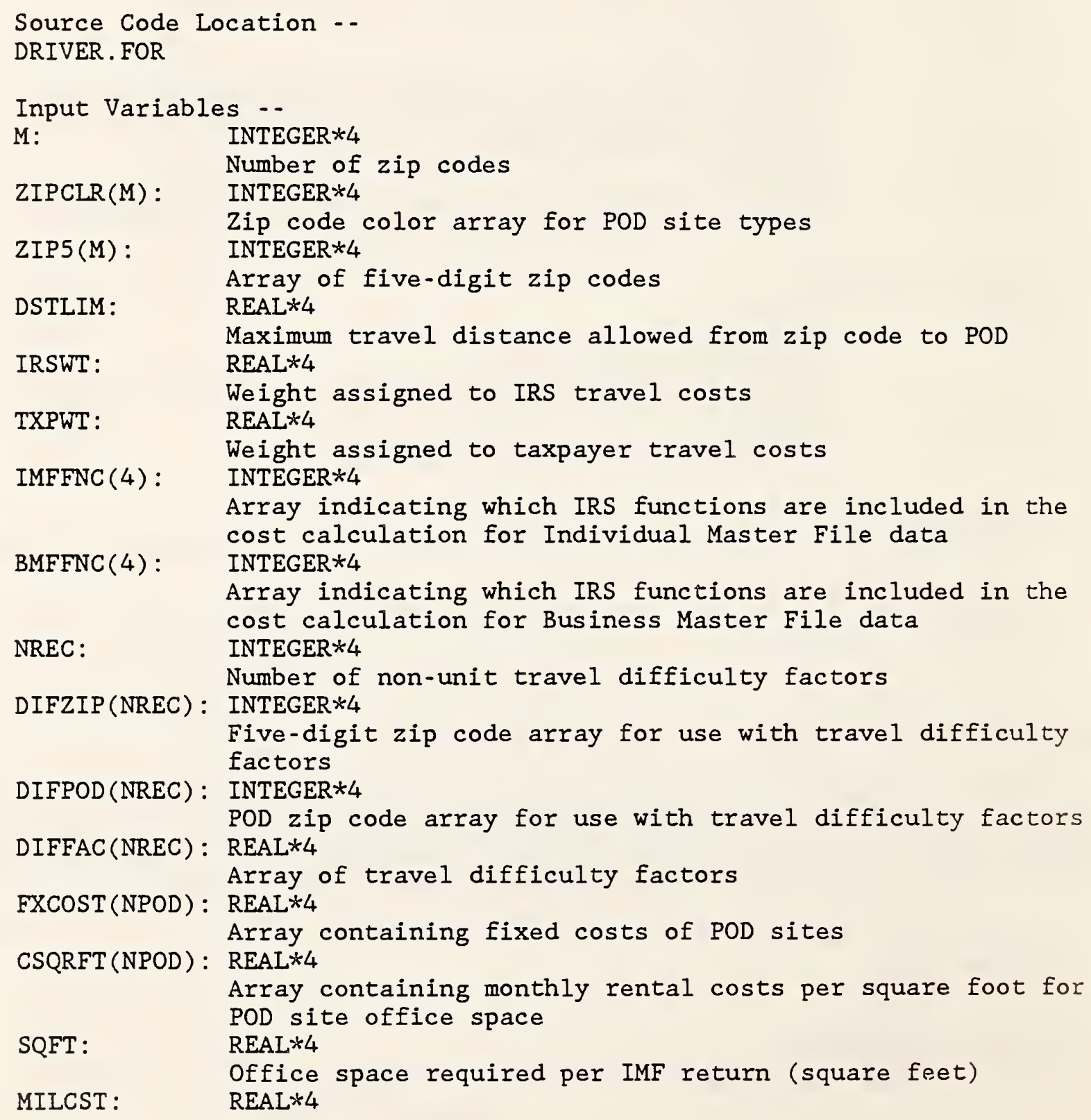




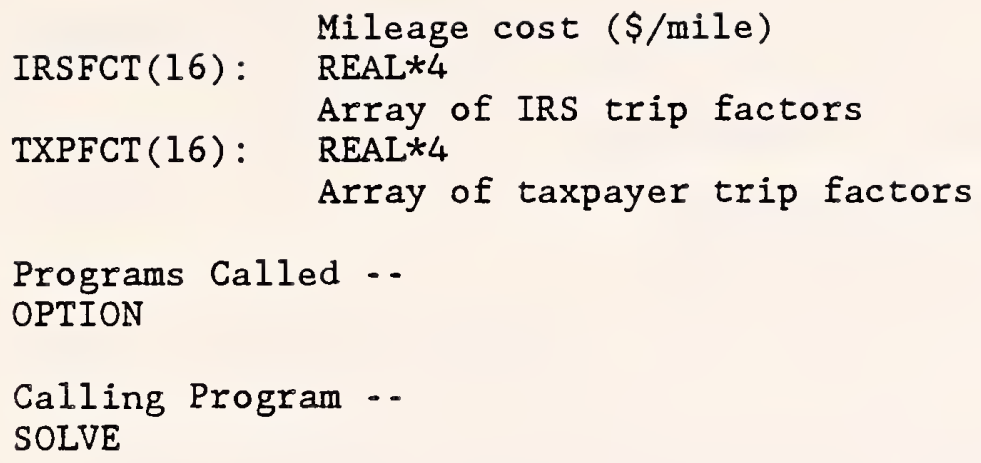

\section{SUBROUTINE REPSOL(COST, NZIP, ZIPIND , NPOD , ENDPNT, ZIP5) :}

This subroutine writes information on the problem solution into the report file.

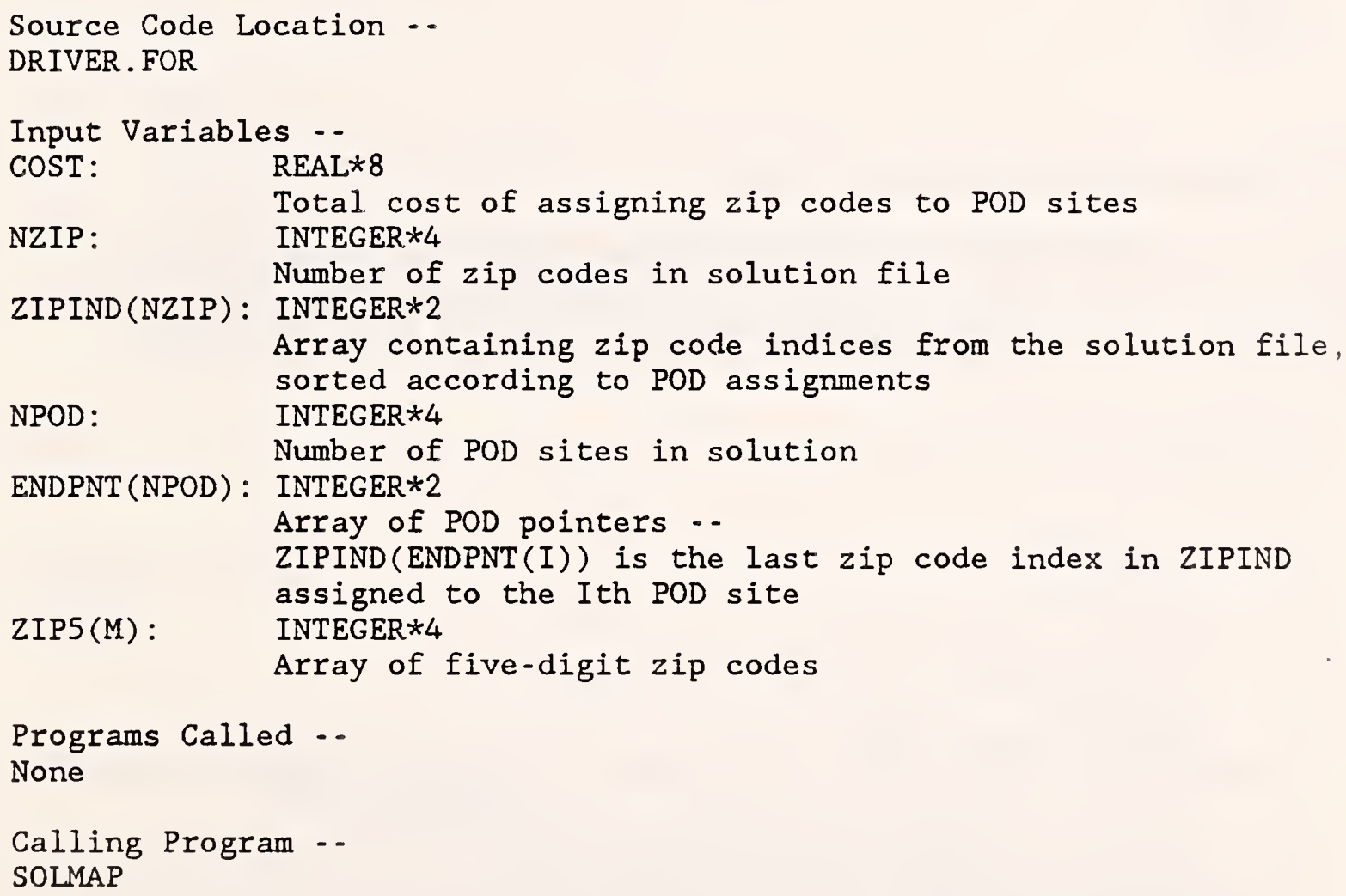

\section{FUNCTION REVERS ( $\mathrm{X}$, MIN, MAX) :}

This function reverses the direction of a coordinate axis. (This is necessary because the $x$ coordinates in the Ganesa files increase from right to left, but GKS assumes that they increase from left to right.)

Source Code Location - - 


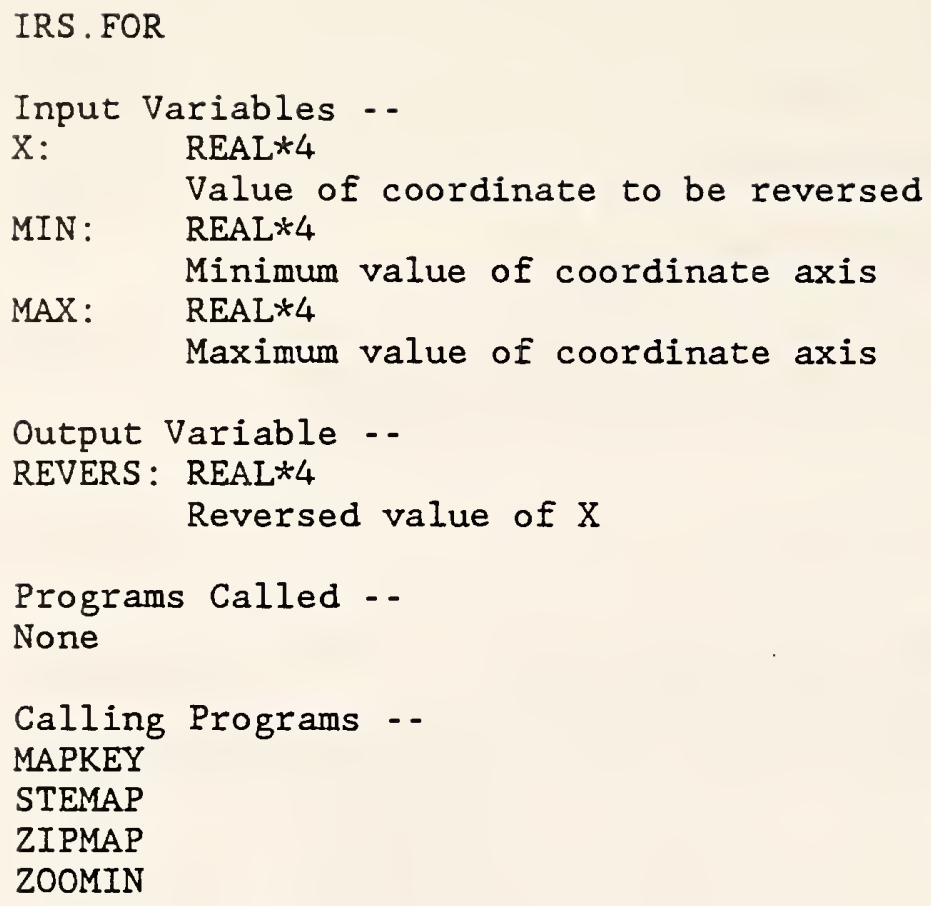

SUBROUTINE SEARCH(XPT, YPT, $\mathrm{M}, \mathrm{X}, \mathrm{Y}, \mathrm{POS})$ :

This subroutine searches the list of sorted centroids to find the centroid closest to a given point. A binary search is done to find the nearest $x$ coordinate, and then a sequential search is done to find the nearest $y$ coordinate.

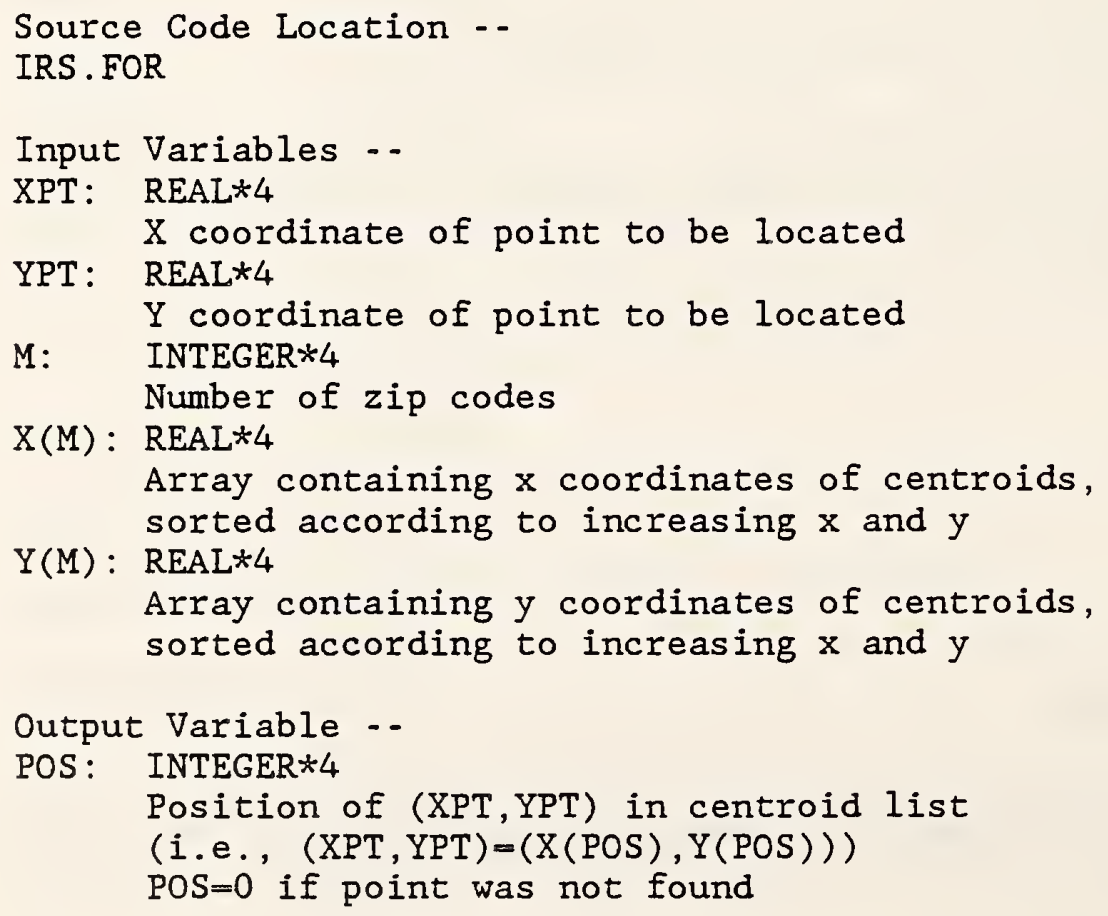


Programs Called -.

None

Calling Program --

MAPKEY

\section{SUBROUTINE SETCOL(WKID, PALETT) :}

This subroutine defines the colors to be used by the display device. The type of display device in use is determined by calling the GKS routine GQCF which returns the number of colors available on the current device driver. For a medium-resolution four-color display, this subroutine sets palette two with a blue background. For an enhanced color display, it sets sixteen colors in one of two possible palettes. (See the GKS manual for definitions of graphics terms.)

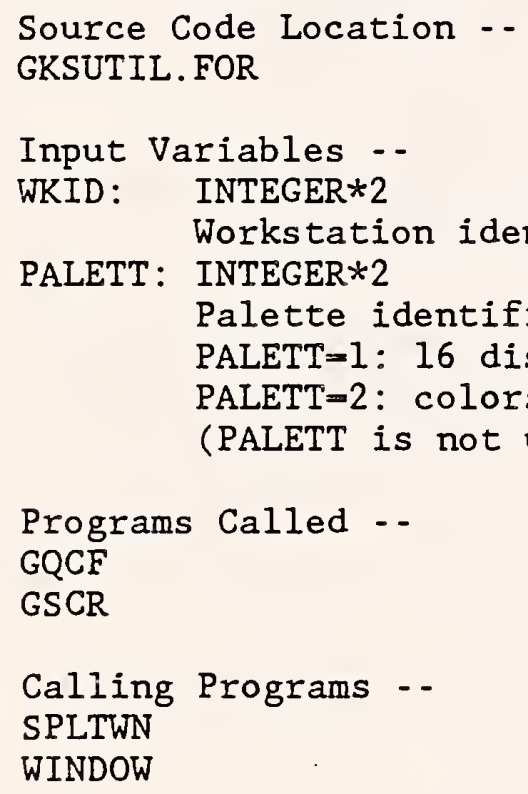

SUBROUTINE SOLMAP (IERR, STATE, PAUSE , M, XCENT, YCENT, INDEX, PNT , ZIPCLR, ZIPS, ZIPIND, ENDPNT) :

This subroutine initializes the display of a solution map. It is executed when the user chooses "F5 - DISPLAY OPTIMAL POD LOCATIONS" from the top menu. It checks the solution file STATEXX.SOL to see whether the graphcoloring algorithm was used by the solver. (This algorithm is used only if an input file is present giving zip code adjacency information.) If graphcoloring was not used, then only zip codes which are POD sites (as determined by the solution) will be colored on the map (using color \#3); all other zip codes will be in the background color (color \#1). (Note: A negative color number indicates that the centroid will be drawn as a small box; otherwise the centroid is an asterisk.) If graph-coloring was used, then a color for each zip code is read from the solution file (the color 
number is increased by one to avoid using the background color). The resulting map will show a POD and its assigned zip codes all in the same color. The subroutine REPSOL is called to write solution information in the report file and the subroutine DISPLY is called to draw the map.

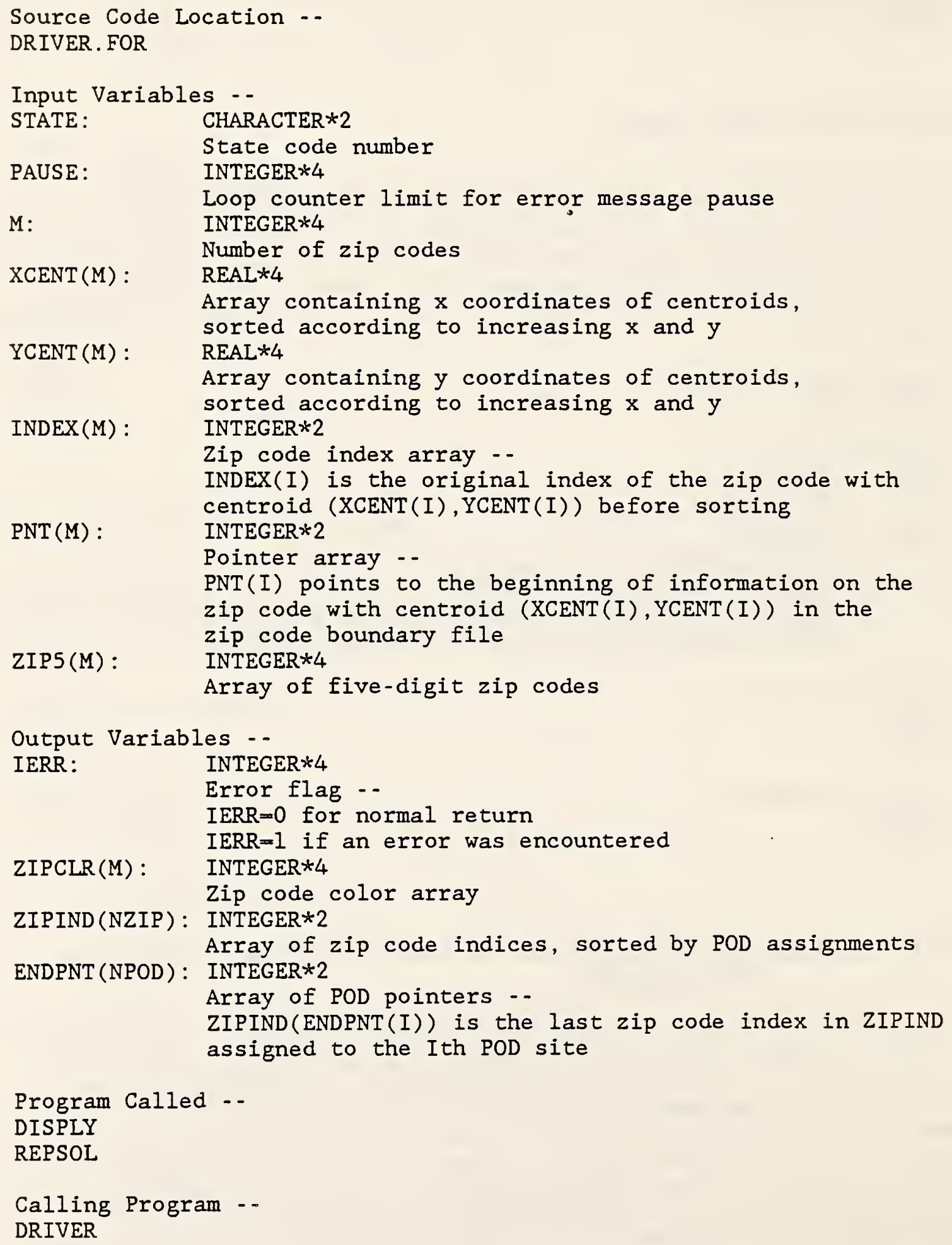

Calling Program -DRIVER 
SUBROUTINE SOLVE(IERR, STATE, PAUSE , MAXPOD , PODZIP , XPOD, YPOD , M , HOLD , FXCOST , CSQRFT, TRVDIF , ZIPCIR, ZIP5 , JCOEF , COST , MAXDIF , DIFZIP , DIFPOD , DIFFAC) :

This subroutine allows the user to set parameters to initialize a location problem and then calculates costs which are passed to the solution procedure SOLVER.COM. It is executed when the user chooses "F4 - SOLVE FOR OPTIMAL POD LOCATIONS" from the top menu. First, opening/closing costs and office rental costs are read from the file STATEXX.POD. If any POD sites exist which are not in the file, the user is asked to enter the costs. Then several parameters such as cost per mile, maximum travel distance, and trip factors are read from the file STATEXX. WRK. The user is allowed to set weights for IRS and taxpayer costs, to turn categories. of workload on or off, to change the distance limit, and to set travel difficulty factors. The parameter settings are summarized in the report file STATEXX.REP.

After all parameters have been set, the program proceeds to calculate costs of assigning zip codes to POD sites. These costs are passed to the PASCAL solution procedure in the unformatted sequential file STATEXX.DBL. For each zip code, the program finds all possible POD sites (current, potential and fixed) within the specified distance limit and calculates the cost of each assignment using the function COSTFN. The assignments are then sorted in order of decreasing cost; if a zip code is a possible POD site, its cost is last in the list. The list of costs and POD sites for a particular zip code is written as one record of the file STATEXX.DBL. The type of the zip code (i.e., whether it is a potential POD site, a fixed POD site, etc.) is also included in the record. The record is padded with zeroes to make the file readable by a PASCAL program. If, for some zip code, there are no possible POD sites within the distance limit, an error message will appear on the screen. Otherwise, the subroutine is exited and control passes to the solution procedure. (The solution algorithm is described in "The Internal Revenue Service Post-of-Duty Location Modeling System: Programmer's Manual for PASCAL Solver".)

Source Code Location -DRIVER. FOR

Input Variables --

STATE: $\quad$ CHARACTER*2

State code number

PAUSE : INTEGER*4

MAXPOD : Loop counter limit for error message pause

M: INTEGER *4 Maximum possible number of POD sites

ZIPCLR(M): INTEGER*4 Number of zip codes

$\operatorname{ZIP5}(\mathrm{M})$ : Zip code color array for POD site types INTEGER *4 Array of five-digit zip codes, in original sequential order

MAXDIF : $\quad$ INTEGER *4 Maximum number of non-unit travel difficulty factors 


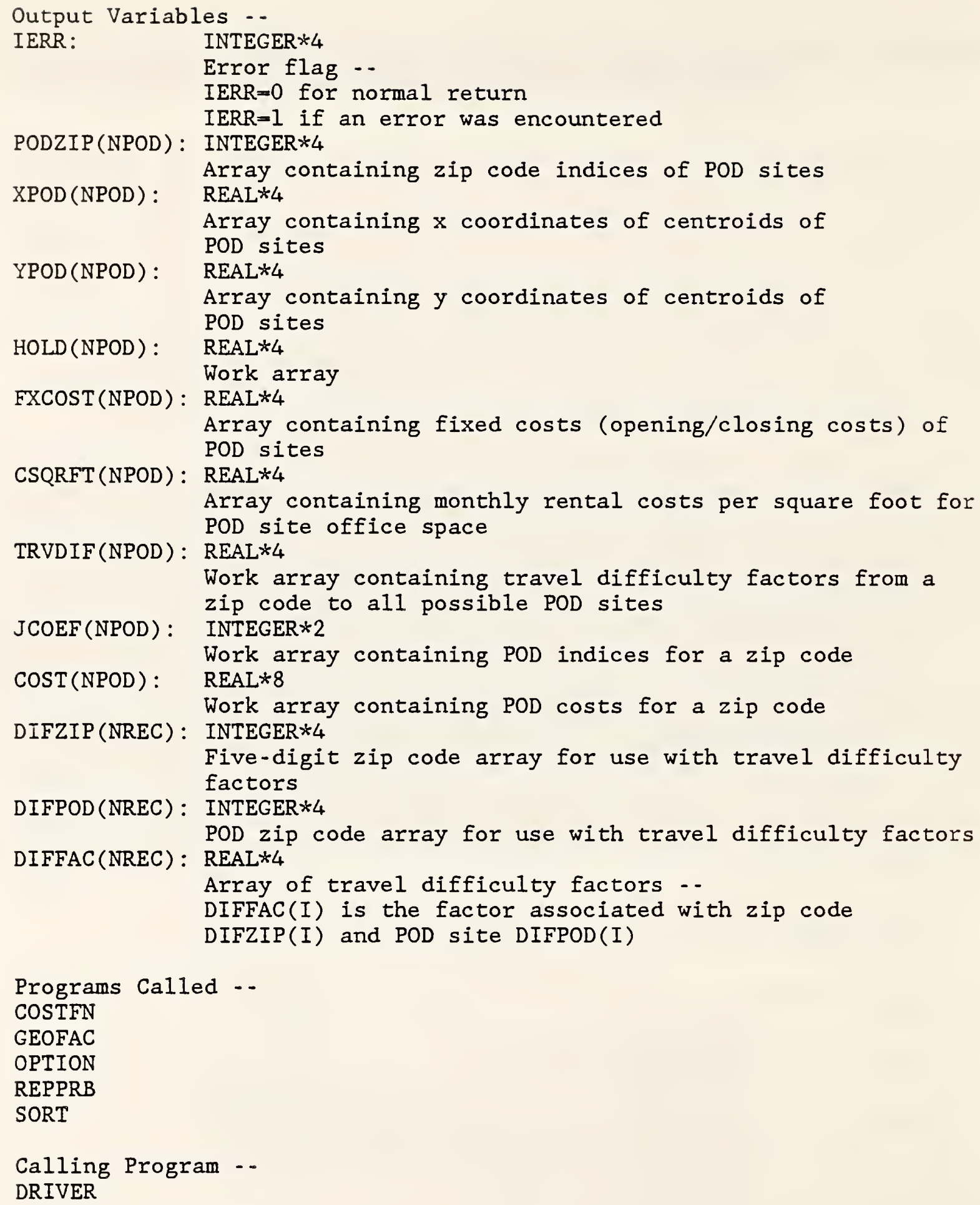

SUBROUTINE SORT(M,X,Y, INDEX, PNT):

This subroutine uses a heapsort algorithm to sort the centroids according to increasing $\mathrm{x}$ and $\mathrm{y}$ coordinates. (It is also used to sort other arrays.) 
For a description of the heapsort algorithm, see, for example, An Introduction to Data Structures with Applications by J. P. Tremblay and P. G. Sorenson (McGraw-Hill, 1976, P. 475).

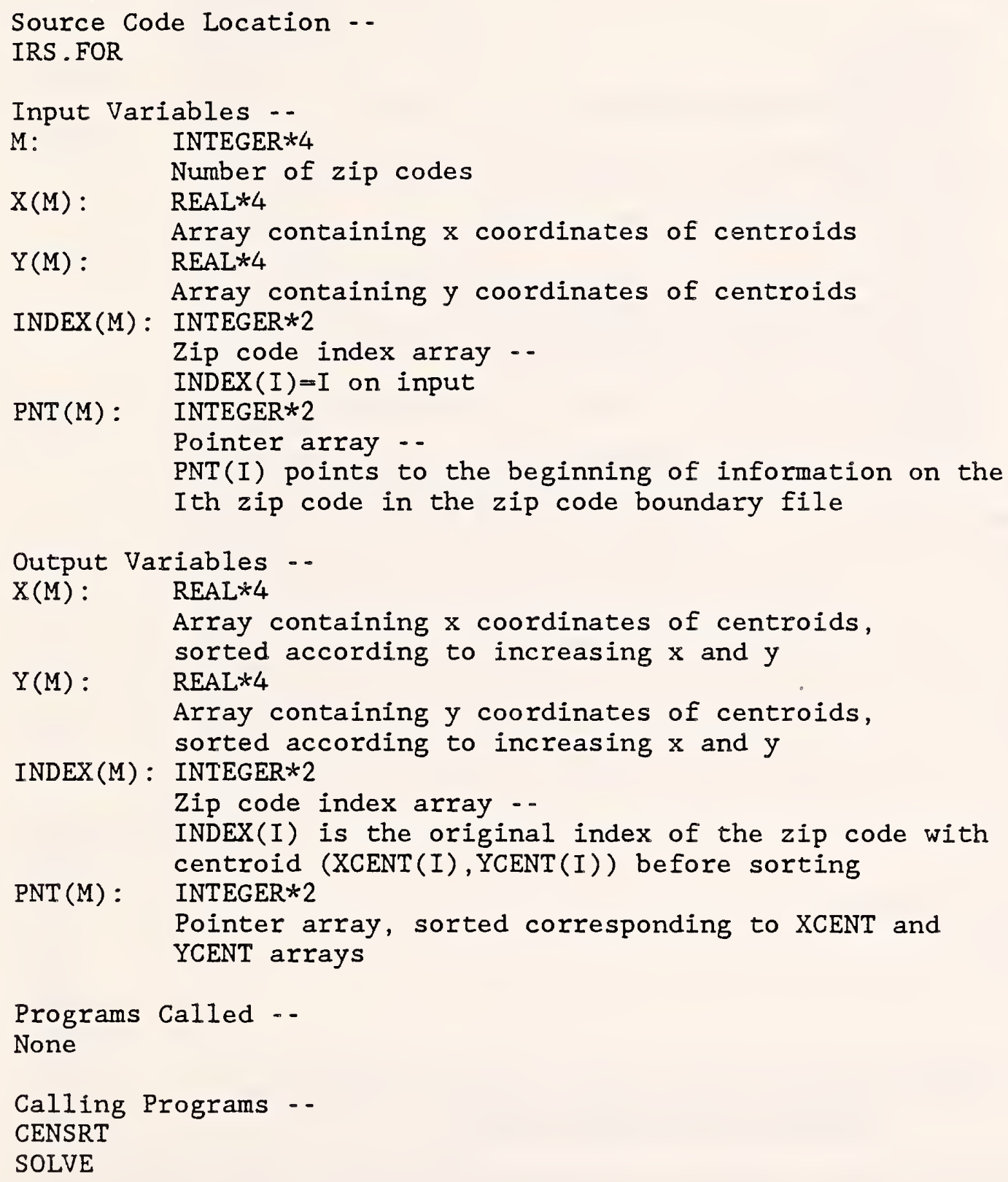

\section{SUBROUTINE SPLT'NN(WKID, RTRN, PALETT, XMIN, XMAX, YMIN, YMAX):}

This subroutine sets up a split window and viewport (designed for a menu on the left side and a map on the right side). World coordinates for the left side must be between 0 and 1 and use transformation number 7 . The width of the left window is set to be the width of eight characters. World coordinates and a transformation number for the right side must be specified 
by the user, and the aspect ratio of the data will be preserved. (See the GKS manual for definitions of graphcis terms.)

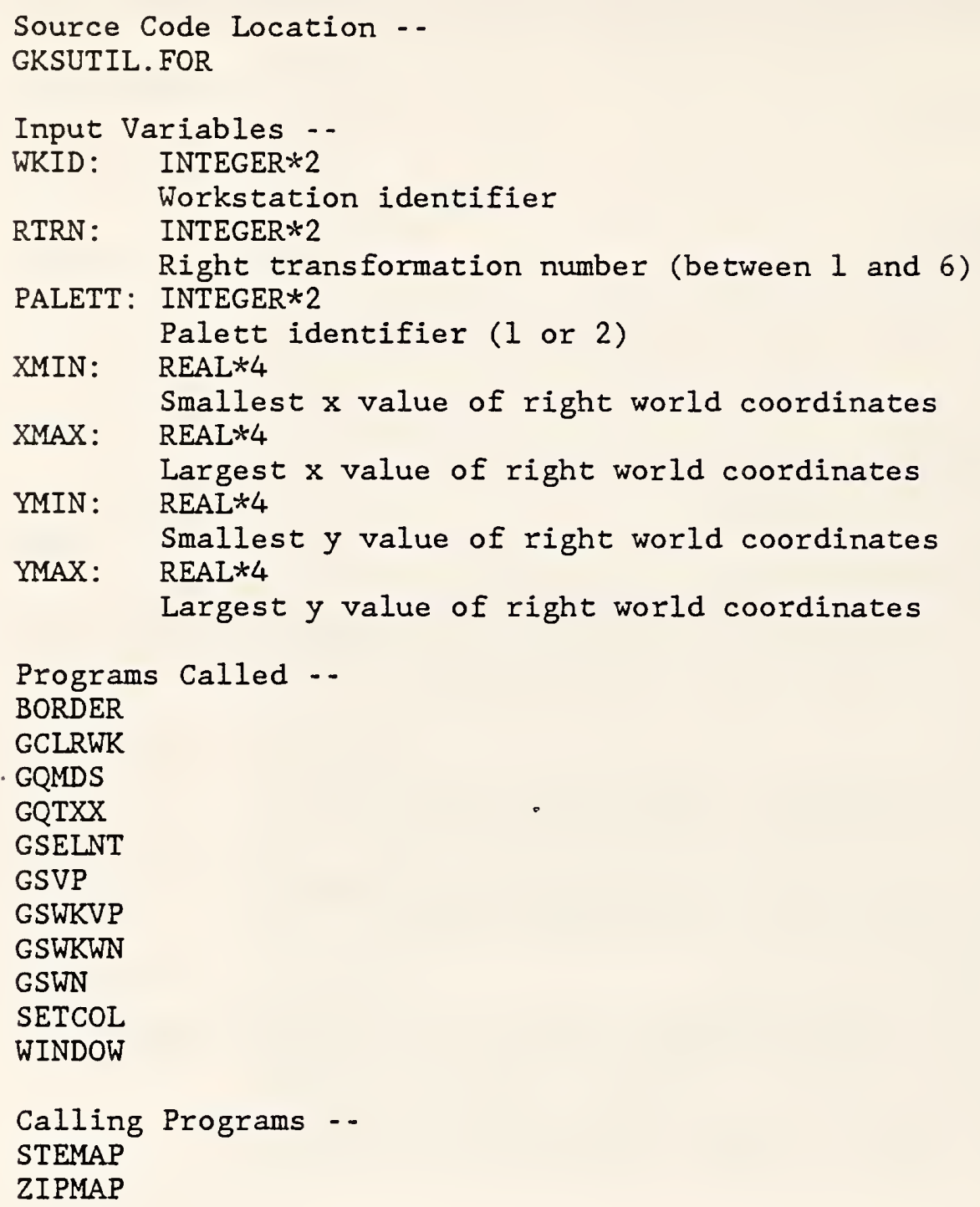

SUBROUTINE STEMAP (IERR, TRN, PALETT, STATE, XMIN, XMAX, YMIN, YMAX, M, XCENT, YCENT, INDEX, ZIPCLR):

This subroutine draws a state map, showing the outline of the state and centroids of zip codes. (Zip code boundaries are not drawn.) The state border is read from the fila STATEXX.STE.

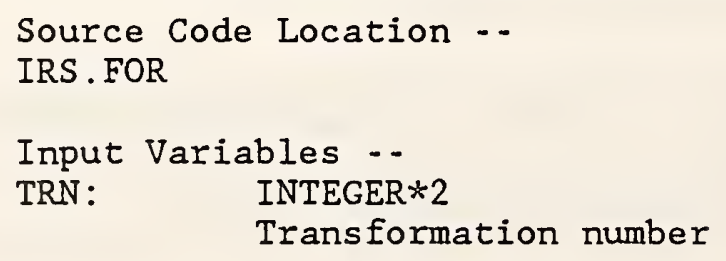




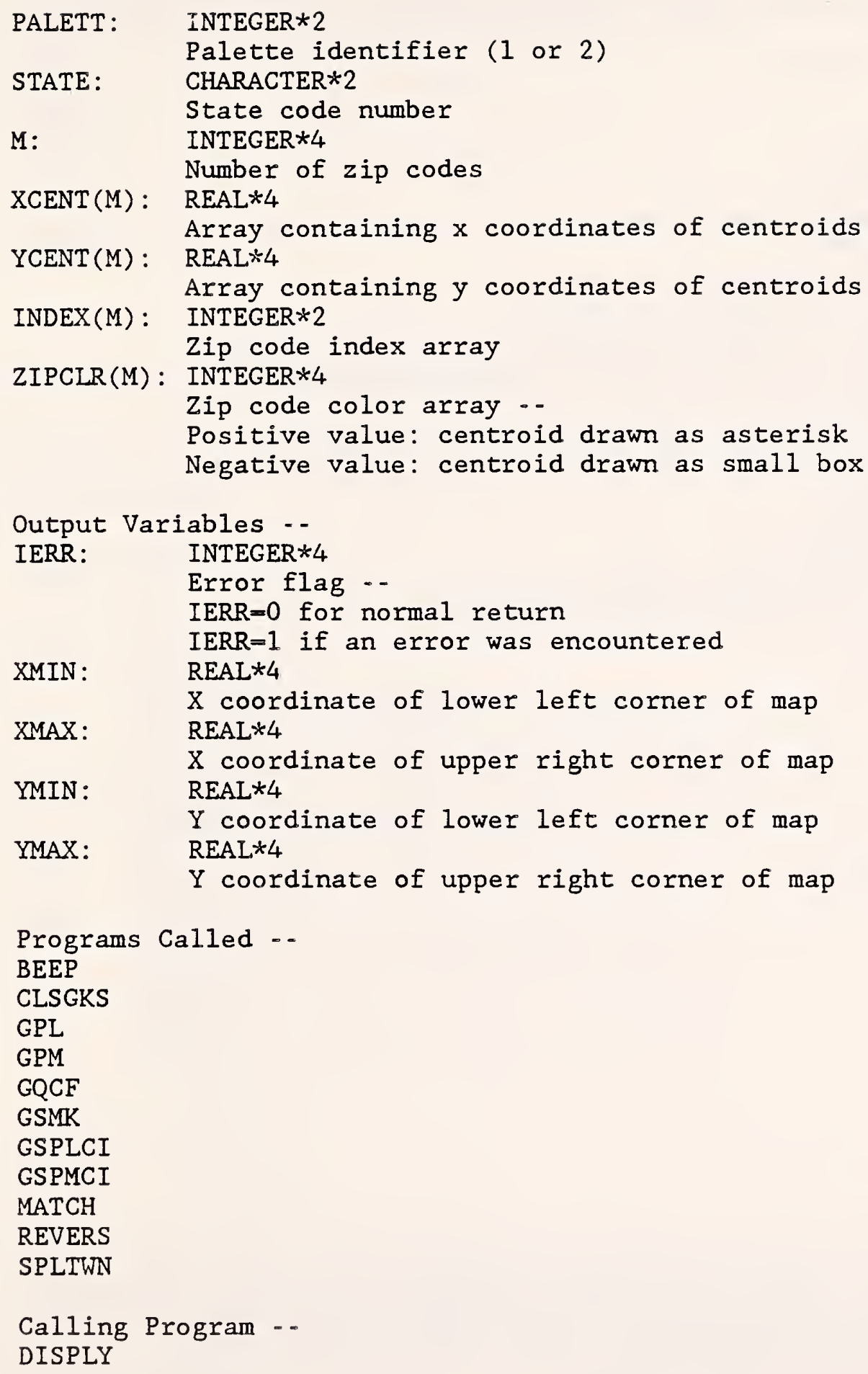

SUBROUTINE STYLE (IERR, WKID, PALETT, INDEX) :

This subroutine sets one of sixteen area-filling interior styles. For a medium-resolution four-color display, the style is either a solid color or a 
cross-hatch pattern. For an enhanced color display, the style is always a solid color. (See the GKS manual for definitions of graphics terms.)

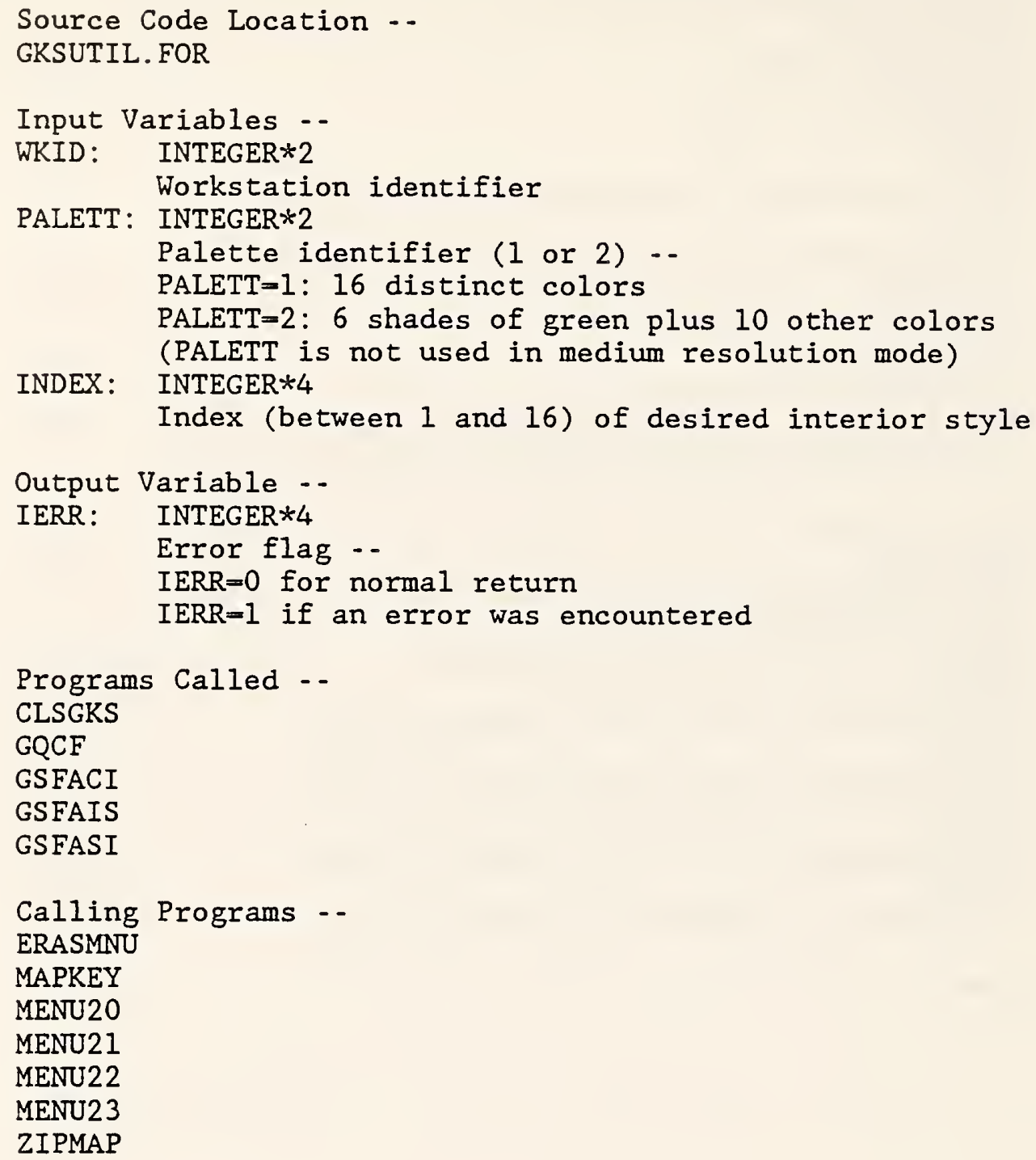

\section{SUBROUTINE TOPMNU:}

This subroutine writes the text for the top-level menu on the screen. The format of the menu is slightly different depending on whether a regular color display or an enhanced color display is being used. This is determined by calling the GKS routine GQCF which finds the number of colors available on the current device driver.

Source Code Location --

DRIVER.FOR

Programs Called -. BORDER 
GPL

GQCF

GSPLCI

GSTXCI

GTX

WINDOW

Calling Program ..

DRIVER

\section{SUBROUTINE WINDOW(WKID, TRN, PALETT, XMIN, XMAX, YMIN, YMAX) :}

This subroutine sets a window and a viewport in a way that preserves the aspect ratio of the world coordinates. (See the GKS manual for definitions of graphics terms.)

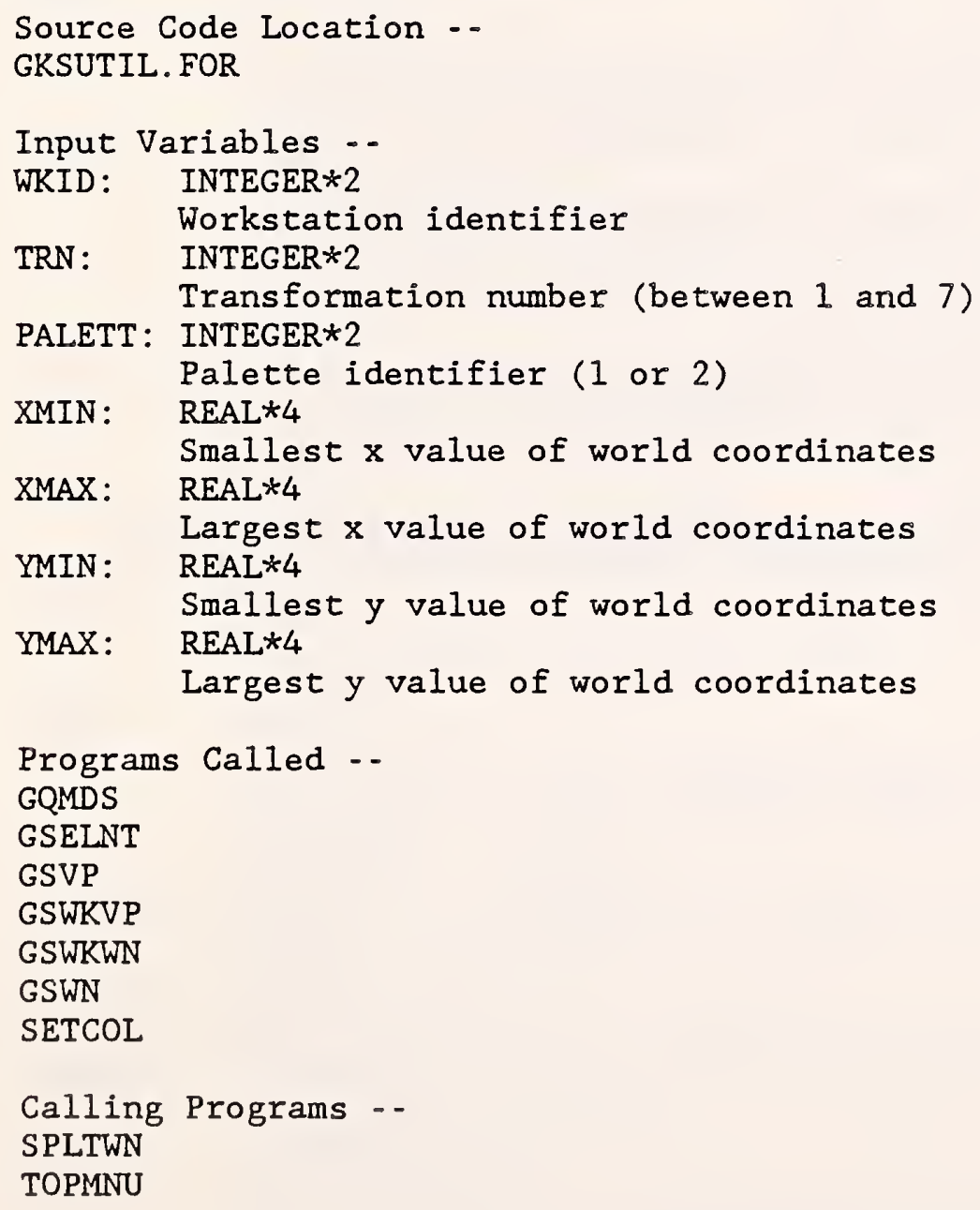

SUBROUTINE WRKMAP (IERR, STATE, PAUSE , M, XCENT , YCENT , INDEX, PNT , ZIPCLR) : 
This subroutine initializes the display of a workload map. It is executed when the user chooses "F2 - DISPLAY WORKLOAD" from the top menu. It first asks the user to choose the category of workload to be displayed and then sets a series of sixteen switches corresponding to the desired columns of the workload file STATEXX.WRK. These columns are read and summed for each zip code. Then the workloads are divided into six equally spaced ranges. Each zip code is assigned a color according to the range its workload falls in. The colors are passed in an array to the subroutine DISPLY which draws the map.

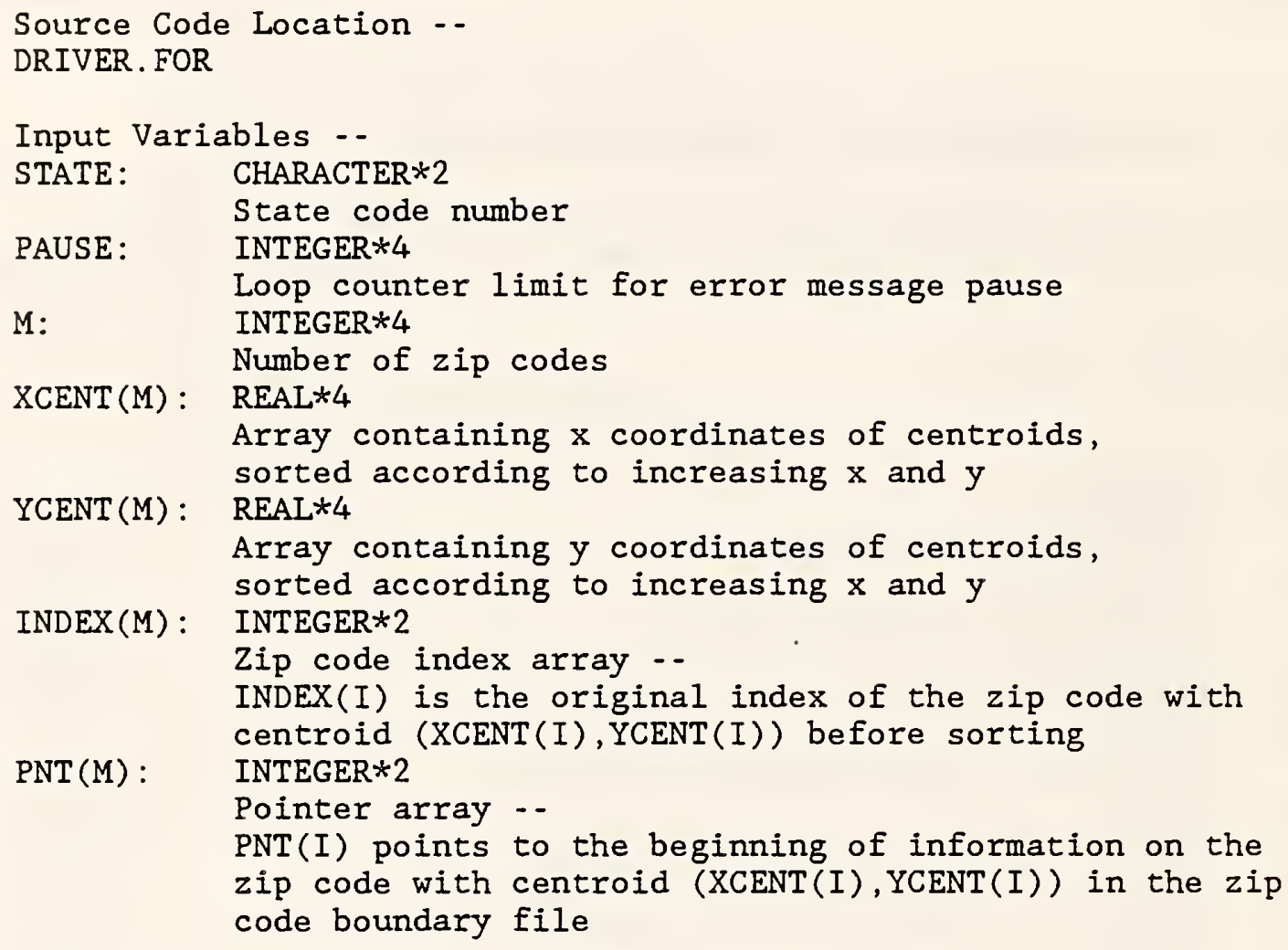

SUBROUTINE ZIPMAP (IERR, TRN, PALETT, STATE, ZOOM, COLOR, XMMN, XMAX, YMTN, YMAX, M, XCENT, YCENT, INDEX, PNT , ZIPCLR) : 
This subroutine draws a zip code map either for a full state or for a smaller area. Centroids are included, and the zip codes are colored if specified. The zip code boundaries are read from the file STATEXX.ZIP. If the whole state is not to be drawn, but only a smaller region specified by a zoom rectangle, a search is done first to find the first and last zip codes (as given in the sorted centroid list) included in the rectangle.

Source Code Location -.

IRS . FOR

Input Variables -.

TRN : $\quad$ INTEGER*2

Transformation number

PALETT: INTEGER*2

STATE: $\quad$ CHARACTER $* 2$

State code number

ZOOM: $\quad$ LOGICAL

Zoom indicator .-

$\mathrm{ZOOM}=$.FALSE. if entire state is to be drawn

ZOOM=.TRUE. if only part of state is to be drawn

COLOR: LOGICAL

Color indicator --

COLOR $=$. TRUE. if zip codes are to be colored as they are drawn

COLOR=.FALSE. if just zip code boundaries are to be drawn

XMIN : $\quad$ REAL*4

$X$ coordinate of lower left corner of zoom rectangle (used only if $\mathrm{ZOOM}=$. TRUE.)

XMAX: $\quad$ REAL $* 4$

$X$ coordinate of upper right corner of zoom rectangle

YMIN : $\quad$ REAL*4

$Y$ coordinate of lower left corner of zoom rectangle (used only if $\mathrm{ZOOM}=$.TRUE.)

YMAX: $\quad$ REAL*4

$Y$ coordinate of upper right corner of zoom rectangle (used only if $\mathrm{ZOOM}=$. TRUE.)

M: $\quad$ INTEGER*4

Number of $z$ ip codes

XCENT (M) : REAL*4

Array containing $\mathrm{x}$ coordinates of centroids

YCENT (M): REAL*4

Array containing y coordinates of centroids

$\operatorname{INDEX}(\mathrm{M})$ : INTEGER*2

Zip code index array

$\operatorname{PNT}(M): \quad$ INTEGER*2

Pointer array --

PNT(I) points to the beginning of information on the zip code with centroid (XCENT(I), YCENT(I)) in the zip code boundary file

ZIPCLR(M) : INTEGER*4

Zip code color array -- 
(colors used only if COLOR=.TRUE.)

Positive value: centroid drawn as asterisk

Negative value: centroid drawn as small box

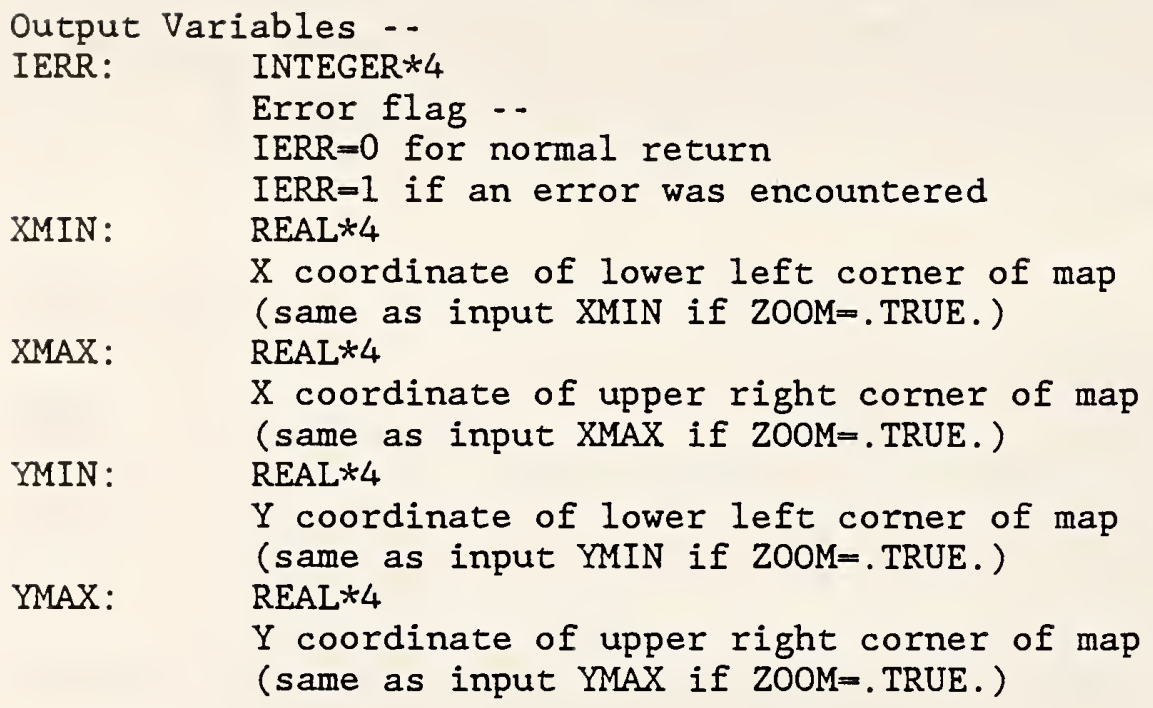

SUBROUTINE ZOOMIN (IERR, TRN, PALETT, STATE, XMIN , XMAX, YMIN , YMAX, M, XCENT, YCENT, INDEX, PNT, ZIPCLR):

This subroutine allows the user to draw a box with the cursor on a previously drawn map and then zooms in on the boxed area.

Source Code Location --

IRS . FOR

Input Variables -.

TRN : $\quad$ INTEGER*2

Transformation number 


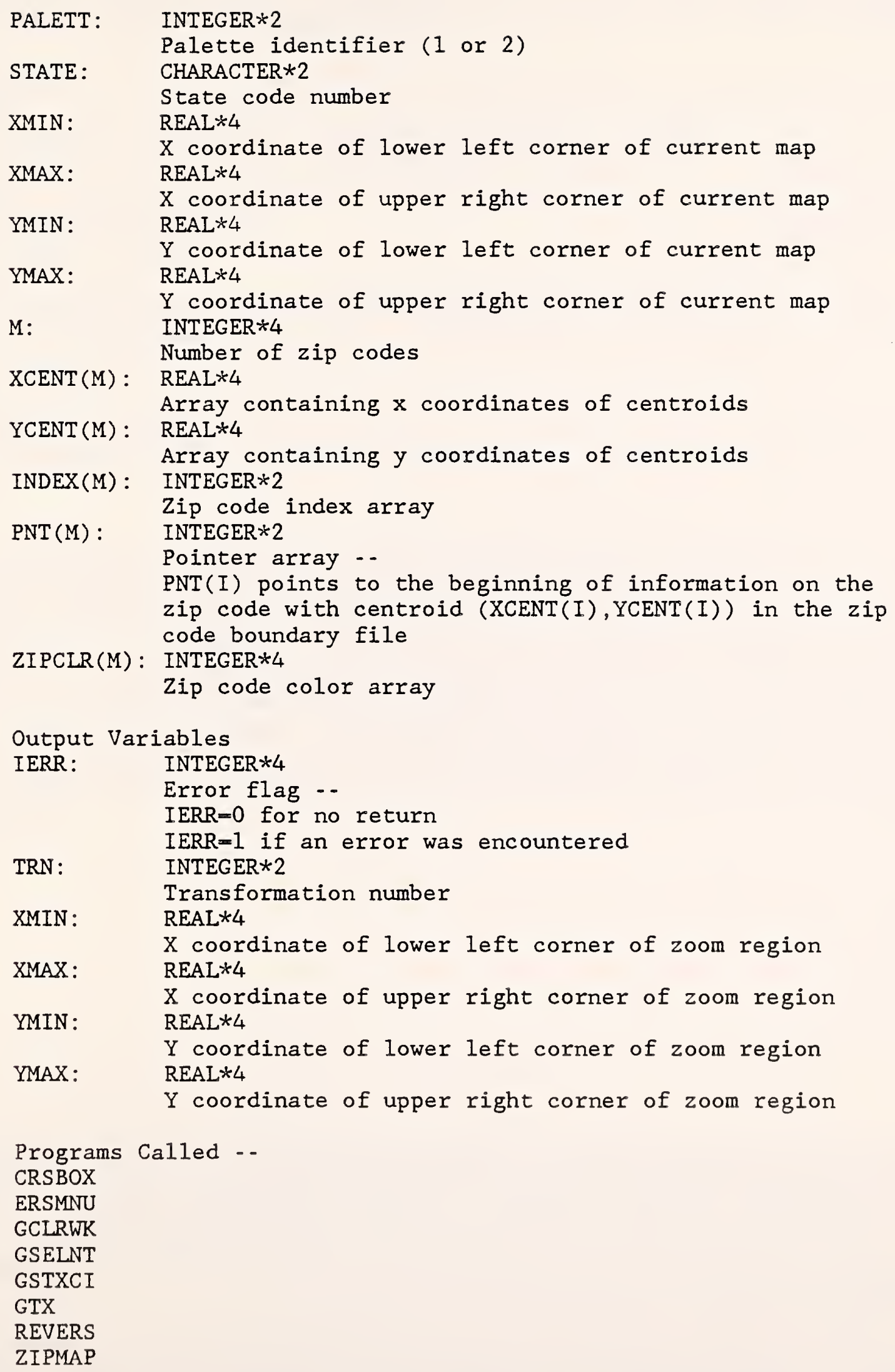


Calling Program - DISPLY 
NBS-114A (REV. 2.8C)

U.S. DEPT. OF COMM.

BIBLIOGRAPHIC DATA

SHEET (See instructions)

1. PUBLICATION OR

REPORT NO.

NBSIR $86-3473$

FEBRUARY 1987

4. TITLE AND SUBTITLE

The Internal Revenue Service Post-of-Duty Location Modeling System -

Programmer's Manual for Fortran Driver

5. AUTHOR(S)

Paul D. Domich, Richard H. F. Jackson, Marjorie A. McClain

5. PERFORMING ORGANIZATION (If joint or other than NBS, see instructions)

7. Contract/Grant No.

NATIONAL BUREAU OF STANDARDS

DEPARTMENT OF COMMERCE

8. Type of Report \& Period Covered

WASHINGTON, D.C. 20234

9. SPONSORING ORGANIZATION NAME AND COMPLETE ADDRESS (Street. City. State, ZIP)

The Research Division

U. S. Internal Revenue Service

1201 E Street

Washington, DC 20224

10. SUPPLEMENTARY NOTES

Document describes a computer program; SF-185, FIPS Software Summary, is attached.

11. ABSTRACT (A 200-word or less factual summary of most significant information. If document includes a significant bibliography or literature survey. mention it here)

This report is a programmer's manual for a microcomputer package which was designed by the National Bureau of Standards to assist the Internal Revenue Service in choosing locations for its posts-of-duty which will minimize costs to the IRS and to the taxpayer. The package was written in two sections of code, one in FORTRAN and the other in PASCAL. This manual describes the FORTRAN driver which handles graphics displays and controls input and output for the solution procedures.

12. KEY WORDS (Six to twelve entries; alphabetical order; capitalize only proper names; and separate key words by semicolons) facility location, interactive graphics, personal computer, microcomputer, Graphical Kernel System (GKS)

13. AVAILABILITY

X Unlimited

For Official Distribution. Do Not Release to NTIS

Order From Superintendent of Documents, U.S. Government Printing Office, Washington, D.C. 20402.

$X]$ Order From National Technical Information Service (NTIS), Springfield, VA. 2216I
14. NO. OF

PRINTED PAGES

55

15. Price

$\$ 13.95$ 


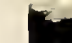

